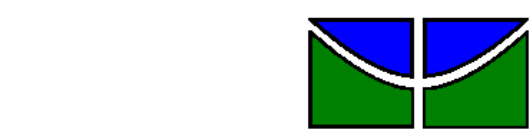

Universidade de Brasília

Faculdade de Economia, Administração e Contabilidade

Departamento de Administração

Curso de Graduação em Administração a distância

MÁRCIO SANTOS FERREIRA

\title{
COMPROMETIMENTO AFETIVO DA EQUIPE DE TRABALHADORES TERCEIRIZADOS EM SETOR DE INFORMÁTICA DE EMPRESA BANCÁRIA
}

Brasília - DF 


\section{MÁRCIO SANTOS FERREIRA}

\section{COMPROMETIMENTO AFETIVO DA EQUIPE DE TRABALHADORES TERCEIRIZADOS EM SETOR DE INFORMÁTICA DE EMPRESA BANCÁRIA}

Monografia apresentada a Universidade de Brasília (UnB) como requisito parcial para obtenção do grau de Bacharel em Administração.

Professor Orientador: Professora Rose Mary Gonçalves 
Ferreira, Márcio Santos.

Comprometimento afetivo da equipe de trabalhadores terceirizados em setor de informática de empresa bancária / Márcio Santos Ferreira. - Brasília, 2011.

50 f. : il.

Monografia (bacharelado) - Universidade de Brasília, Departamento de Administração - EaD, 2011.

Orientador: Profa. Msc. Rose Mary Gonçalves, Departamento de Administração.

1. Satisfação. 2. Comprometimento. 3. Empregado terceirizado. 


\section{MÁRCIO SANTOS FERREIRA}

\section{COMPROMETIMENTO AFETIVO DA EQUIPE DE TRABALHADORES TERCEIRIZADOS EM SETOR DE INFORMÁTICA DE EMPRESA BANCÁRIA}

A Comissão Examinadora, abaixo identificada, aprova o Trabalho de Conclusão do Curso de Administração da Universidade de Brasília do

(a) aluno (a)

\section{Márcio Santos Ferreira}

Profa. Msc. Rose Mary Gonçalves

Professor-Orientador

Profa. Dra. Gisela Demo Fiuza

Professor-Examinador

Brasília, 09 de Abril de 2011 


\section{RESUMO}

A interação do trabalhador com sua equipe de trabalho apresenta reflexos no seu comprometimento tanto com os colegas de trabalho quanto com a empresa contratante. Para investigar tais relações, este estudo teve como objetivo analisar o comprometimento afetivo da equipe de trabalhadores terceirizados em setor de informática de empresa bancária. Para medir as variáveis, foi realizada uma pesquisa survey com método de análise quantitativo. $O$ instrumento utilizado para coleta dos dados foi o questionário Escala, Satisfação e Comprometimento de Equipes, um questionário com 14 questões fechadas, a fim de obter respostas claras e precisas, visando à caracterização da realidade em estudo. Os resultados obtidos nas análises revelaram que existe comprometimento afetivo entre os trabalhadores da instituição bancária que atuam no setor de informática

Palavras-chave: Gestão de Pessoas; comprometimento afetivo com equipe; comprometimento organizacional. 


\section{SUMÁRIO}

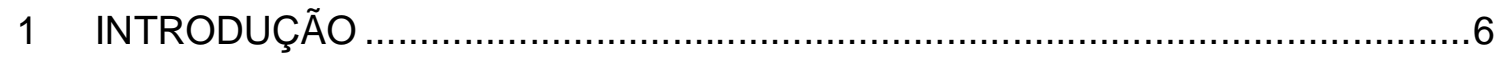

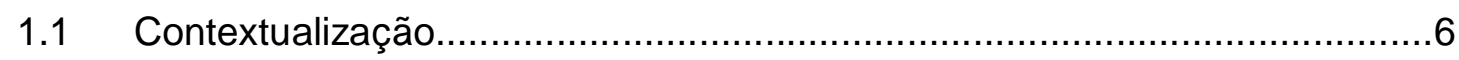

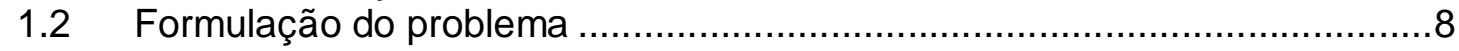

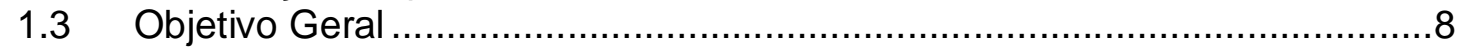

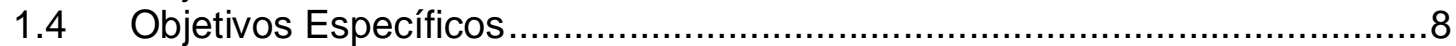

1.5 Justificativa

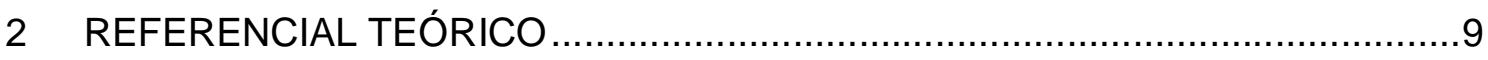

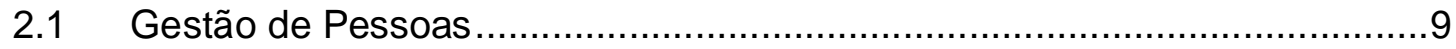

2.2 Motivação no ambiente de trabalho ....................................................12

2.3 Clima Organizacional ...............................................................15

2.4 Comprometimento Organizacional e afetivo ………….........................18

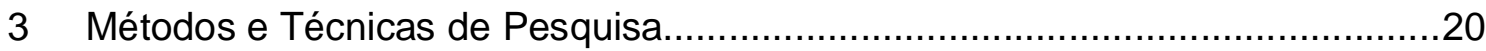

3.1 Caracterização da organização, setor ou área.........................................20

3.2 População e amostra ou participantes do estudo .....................................20

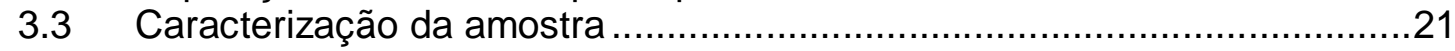

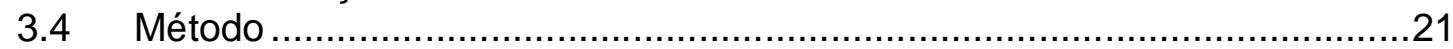

3.5 Caracterização dos instrumentos de pesquisa.......................................22

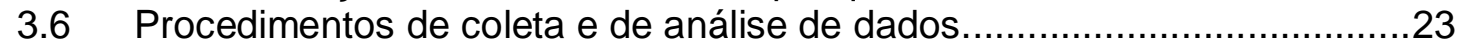

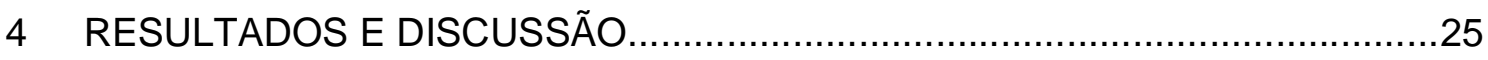

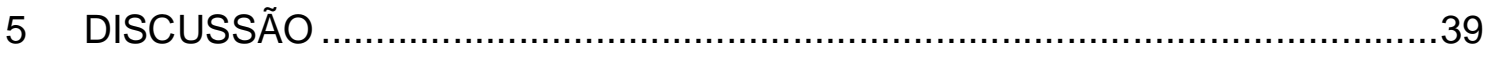

6 CONCLUSÕES E RECOMENDAÇÕES ……….......................................42

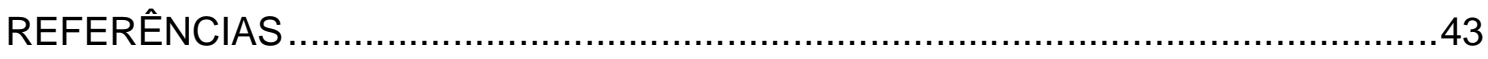

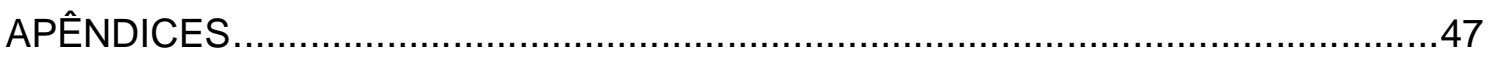

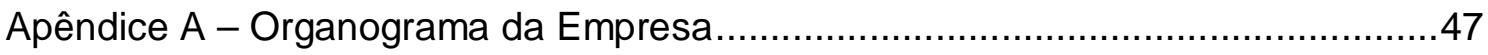

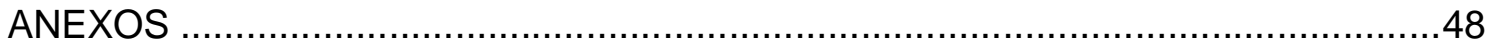

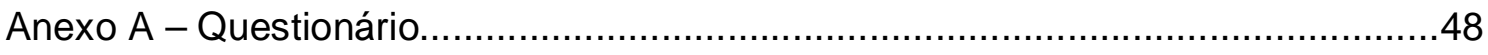




\section{INTRODUÇÃO}

\subsection{Contextualização}

A busca pela consecução de melhores resultados tem motivado as organizações a desenvolverem sua capacidade estratégica para enfrentar as mudanças e desafios no contexto da economia globalizada. Desta forma, em busca de obter sucesso no mundo dos negócios, as empresas têm superado diversos desafios, e para isto utilizam estratégias variadas.

Neste cenário, paralelamente a este crescimento, surge a preocupação das empresas com a melhoria dos serviços no atendimento aos clientes, pois o nível de exigência dos consumidores e a concorrência no mercado crescem juntamente com a importância do setor.

A globalização da economia é um fator determinante para a competitividade entre as empresas de todos os setores da economia.

Nesse sentido, a terceirização tem se apresentado como uma alternativa eficaz, uma vez que possibilita a redução de custos para as empresas, tornando mais eficiente sua atividade-fim.

A transferência de atividades secundárias por parte de uma organização a fornecedores externos constitui uma estratégia para assegurar maior eficiência e especialização de suas competências. A terceirização bem-sucedida pode trazer à contratante benefícios como "a contenção e redução de custos, o acesso a inovações, a expansão da oferta de serviços, além da possibilidade de focar-se apenas nas atividades centrais" (QUEIROZ, 1998).

Basicamente, a terceirização é motivada por três propósitos básicos: a diluição dos custos diretos e indiretos; a elevação do nível de eficiência dessa atividade, pela sua execução terceirizada; e a manutenção de um nível mínimo aceitável de lealdade à empresa, por parte dos novos executores das atividades terceirizadas (VALENÇA e BARBOSA, 2002). 
Segundo Batista 1994 (apud VALENÇA e BARBOSA, 2002), o indivíduo que adquire identidade com a cultura organizacional de uma empresa envidará esforços para que os objetivos dela sejam alcançados. Por outro lado, se ele não consegue incorporar essa identificação ou há um desvirtuamento de sua identidade cultural com a de outros membros, consciente ou inconscientemente, ele se dedicará menos ou atuará negativamente para o atingimento dos objetivos organizacionais.

A terceirização traz uma cultura diversa à contratante, que pode interferir ou até mesmo colocar em risco a sobrevivência da empresa. Quando a interação entre empregados e terceirizados é constante e a externalização das atividades não essenciais deveu-se visivelmente sob o enfoque da redução de custos, é possível que se dê a ignição de mini-conflitos que passem a minar o comprometimento mútuo entre os grupos. Contratante e contratada passam a apresentar comportamentos que prejudicam a parceria e a harmonia profissional, o que pode afetar o desempenho das atividades de ambas as partes (PRADO; TAKAYOKA, 2002).

Nesse contexto, poder entender os pontos de vista contrastantes que se formam nos relacionamentos inter-empresariais é uma vantagem para se conseguir buscar o equilíbrio necessário ao exercício das atribuições de cada um. Tais relacionamentos, extremamente comuns e cada vez mais complexos, demandam cuidados e considerações tais quais se dão àqueles entre indivíduos, não só pela vantagem econômica, como pelo próprio respeito ao trabalhador terceirizado.

As diferenças de percepção entre empregados do quadro da contratante e entre terceirizados apresentam impactos que atingem desde 0 desempenho, passando pelo sentimento de integração, cooperação, confiança e até dignidade. Assim, o envolvimento que se busca obter para maximizar a eficiência de todas as partes no processo de externalização de atividades deve considerar o sentimento envolvido pelos indivíduos que executam o serviço terceirizado.

A análise teórica empreendida neste estudo contribuirá para a prática profissional, possibilitando o contato do acadêmico com a realidade do mundo dos negócios e os constantes desafios que surgem a cada dia.

Durante as atividades práticas o acadêmico tem a possibilidade de vivenciar os conhecimentos teóricos adquiridos no decorrer do curso e de se preparar para o mercado de trabalho. 


\subsection{Formulação do problema}

Existe comprometimento afetivo da equipe de trabalhadores terceirizados que atuam no setor de informática de uma empresa bancária?

\subsection{Objetivo Geral}

Analisar o comprometimento afetivo da equipe de trabalhadores terceirizados em setor de informática de empresa bancária.

\subsection{Objetivos Específicos}

a) Analisar o conceito de clima organizacional;

b) Realizar pesquisa em campo com trabalhadores do setor de informática de uma instituição bancária para conhecer seu nível de comprometimento afetivo com sua equipe de trabalho;

c) Discorrer sobre a gestão de pessoas e a importância da motivação no ambiente de trabalho;

d) Definir comprometimento organizacional e afetivo

\subsection{Justificativa}

As pessoas, em seu ambiente de trabalho, recebem influência do grupo em que está inserido que refletem diretamente em seu desempenho.

O modo com que as pessoas se relacionam em seu ambiente de trabalho são indicadores de seu nível de satisfação pessoal e profissional e também preditores de seu comprometimento organizacional e afetivo. 
Os conflitos podem influenciar de forma negativa o comprometimento afetivo do indivíduo com a equipe e com a organização, levando a ter desmotivação para realizar suas tarefas, podendo apresentar declínio em sua produtividade.

O comprometimento afetivo está diretamente relacionado ao vínculo que o indivíduo estabelece com seus colegas de equipe e com a organização. Mensurar o nível deste comprometimento é de suma importância para conhecer pois reflete também o valor que atribui ao seu trabalho, aos seus colegas e à organização de uma forma geral.

\title{
2 REFERENCIAL TEÓRICO
}

\subsection{Gestão de Pessoas}

No limiar do terceiro milênio, o modelo de gestão de recursos humanos evidencia a necessidade de valorização das pessoas para sobreviver em espaços competitivos gerados pela globalização e pelo neoliberalismo. As organizações de hoje enfrentam um ambiente cada vez mais dinâmico e mutante. Isso exige que elas se adaptem às novas condições.

Cabe ressaltar que a economia mundial deste final de século passou por significativas transformações, representadas pela consolidação de um novo paradigma tecnológico-industrial, baseado na microeletrônica e da redefinição dos fatores determinantes da competitividade - o avanço do processo de globalização tem provocado intensos debates. (OLIVEIRA, 2004). Na perspectiva de Borges (2001, p.1):

\begin{abstract}
A globalização compreende um processo de integração mundial que se baseia na liberalização econômica. Através da extinção paulatina de barreiras tarifárias que protegem uma determinada produção da concorrência estrangeira, os países se abrem ao fluxo internacional de bens, serviços e capitais. Este ambiente ocasiona o crescimento das corporações transnacionais, que exercem papel decisivo na economia internacional.
\end{abstract}

Dessa forma, longe de ser um processo já acabado, a globalização se constitui uma tendência da economia mundial à integração do capital e dos investimentos em nível global. A globalização trouxe um grande volume de informações cuja necessidade de absorção é imprescindível às organizações. Para 
que isso aconteça, elas dependem do seu mais valioso recurso que são as pessoas, capazes de transformar informações em conhecimento, tornando-as competitivas (COUTINHO et al, 2008).

Assim, a internacionalização da economia ampliou a atuação de empresas no mundo todo e muitos investimentos financeiros passaram a ser realizados ao redor do mundo. Esta disseminação das atividades econômicas propiciou a transformação dos mercados internos dos países, proporcionando o fortalecimento de vários setores de sua economia (CORRÊA, 2004). Diante deste panorama, se torna impossível pensar em Gestão de Pessoas sem considerar as dimensões culturais nas quais os grupos encontram-se imersos.

Com a crescente competitividade no mundo dos negócios, a valorização do capital humano torna-se uma ferramenta para o sucesso das empresas e este se apresenta com um grande desafio para os administradores neste novo milênio. É do conhecimento e das habilidades dos indivíduos que depende a competitividade das empresas na atualidade (LIMA \& URBINA, 2002).

\begin{abstract}
A busca de maior competitividade, por parte das empresas, vem provocando novas exigências nos perfis profissionais demandados. Essas exigências ligadas ao avanço da automação e a difusão dos novos métodos da organização da produção e do trabalho requerem novas capacidades, derivadas da necessidade de adaptação a um mercado cada vez mais imprevisível e dinâmico. (LIMA \& URBINA, 2002, p.4)
\end{abstract}

A Administração de Recursos Humanos percorreu um longo caminho até chegar à Era da Informação. As organizações de hoje percebem que seu principal ativo não é o financeiro e sim o humano, que é um capital difícil de ser contabilizado, mas que dá a empresa um grande diferencial, ou seja, é considerado como seu fator de competitividade (COUTINHO et al, 2008).

Verifica-se que as organizações, para manterem-se competitivas, mudaram sua concepção, pois seu foco passou a ser a ênfase na mudança e inovação e, por viverem em um ambiente em constante turbulência, seu pensamento em relação às pessoas também se modificou. Diante disso, surge a necessidade das pessoas serem vistas como seres humanos que pensam e que possuem capacidade para fazer uma organização obter resultados satisfatórios ou não.

$\mathrm{Na}$ atualidade a eficiência organizacional tem tido reflexos em função das novas tecnologias que afetam a organização, processamento e uso da informação. A configuração na forma de fazer negócios também foi atingida, pois as bases da competição estão se transformando, a relação entre antigos rivais se re-configura, 
onde a existência de redes e parcerias de negócios se torna constante (ANDRADE, 2005). Neste sentido, é importante que as empresas, na atualidade, a fim de obterem sucesso, desenvolvam novas posturas em relação à administração dos recursos humanos.

Os objetivos da Gestão de Pessoas é desenvolver condições organizacionais de satisfação das pessoas, alcançando os objetivos individuais e desenvolver um contingente de pessoas com habilidades para satisfazer os objetivos da organização.

A Gestão de Pessoas nas organizações é a função que permite a colaboração eficaz das pessoas - empregado, funcionários, recursos humanos ou qualquer denominação utilizada - para alcançar os objetivos organizacionais e individuais (CHIAVENATO Apud COUTINHO et al, 2008, p.4).

Neste contexto, é importante que os administradores estejam atentos para a relação existente entre motivação, satisfação e desempenho no trabalho, pois se o colaborador mantiver um bom nível de motivação, também terá maior probabilidade de exercer melhor sua função dentro da organização. Para tanto, é preciso que o próprio administrador se considere um ator sujeito às influências de seu ambiente e busque:

A valorização das pessoas pressupõe, acima de tudo, o reconhecimento de que eles são seres humanos e têm necessidade e anseios específicos, que precisam ser claramente entendidos e utilizados no desenvolvimento das estratégias, planos e práticas organizacionais, promovendo o alinhamento necessário para o sucesso da organização. (ARAÚJO, 2008, p.7)

Dito em outras palavras, as organizações precisam ter uma visão clara que 0 ser humano é formado por características de personalidade únicas e complexas, e, que seu comportamento no trabalho é influenciado por diversos fatores. Deve-se considerar também que quando o trabalhador é ignorado, sua tendência é sentir-se desmotivado. Face ao exposto, verifica-se que na atualidade, existe um grande desafio para os profissionais que atuam com a gestão de pessoas, pois se vive num contexto de rápidas transformações.

No novo paradigma de gestão, o desenvolvimento profissional ganhou mais importância, trazendo à tona a emergência do trabalhador ser tratado como indivíduo, como sujeito que ele é. 


\subsection{Motivação no ambiente de trabalho}

A palavra motivação vem do latim motivus, que é relativo a movimento ou coisa móvel. A palavra motivação, devido à sua origem, significa movimento. Dessa forma, quem motiva uma pessoa provoca um novo ânimo, e ela começa a agir em busca de novos horizontes e novas conquistas (NAKAMURA, 2005). De acordo com Vergas apud Fiorelli (2004, p.118), "a motivação é uma força, uma energia que nos impulsiona na direção de alguma coisa que nasce de nossas necessidades interiores".

O estudo realizado por Tamayo \& Pachoal (2003) sobre a motivação no trabalho evidencia que existe uma relação entre motivação, comportamento e desempenho que se estabelece espontaneamente. O comportamento é provocado e guiado por metas da pessoa, a qual atinge determinado objetivo a partir de um esforço. A motivação humana é um processo psicológico que está diretamente relacionado com o impulso ou com a tendência do indivíduo em realizar com persistência determinados comportamentos.

A motivação pode ser classificada em: intrínseca e extrínseca. A motivação intrínseca é uma força que se encontra no interior de cada indivíduo. É ela que leva os indivíduos à ação, pois está relacionada a um desejo (BERGAMINI, 1997).

A motivação extrínseca está relacionada a tudo que se encontra exterior ao indivíduo e que quando não está presente causa mal-estar ao indivíduo.

Segundo Salanova, Hontagas \& Peiró apud Gondim \& Silva (2004, p. 146), a motivação pode ser definida como "uma ação dirigida a objetivos, sendo autoregulada, biológica ou cognitivamente, persistente no tempo e ativamente por um conjunto de necessidades, emoções, valores metas e expectativas".

Os principais aspectos relacionados no conceito de motivação são: ativação, direção, intensidade e persistência. Estas são as quatro ênfases a partir das quais se estuda o fenômeno da motivação. A ativação é o estado inicial de estimulação na qual se encontra a pessoa. A direção é o objeto ou alvo de ação intensidade é está relacionada à variabilidade da força de ação e a persistência diz respeito à compreensão do fenômeno motivação interligando ativação, direção e intensidade, sendo que sua manutenção pode estar relacionada a fatores ambientais ou pessoais (GONDIM \& SILVA, 2004). 
A análise desta teoria deve refletir que a motivação está relacionada ao processo de percepção do individuo bem como aos estímulos ambientais que influenciam seu comportamento.

Uma das teorias de motivação mais célebres é a Teoria dos Dois Fatores, ou Teoria Bifatorial, elaborada pelo psicólogo Frederick Herzberg. Segundo ele, existem dois fatores que motivam e satisfazem as pessoas. Estes fatores podem ser motivadores ou higiênicos (MEYER, 2007).

\begin{abstract}
Os fatores motivadores são intrínsecos, ou seja, inerentes à própria pessoa como realização, crescimento e responsabilidade. Quando esses fatores são ótimos, eles elevam substancialmente o nível de motivação dos colaboradores. Já os fatores higiênicos são extrínsecos, e sua ausência causa mal estar nas pessoas. Pode-se citar como exemplo de fatores higiênicos a supervisão, as condições de trabalho, o salário, 0 relacionamento com os colegas (Meyer, 2007, p.1)
\end{abstract}

Assim sendo, nesta concepção observa-se a motivação parte do interior do indivíduo, ou seja, ele é movido pro fatores intrínsecos e que ele age em determinadas situações em função dos fatores extrínsecos.

Outra Teoria de Motivação proposta pelo psicólogo Abrahan Maslow, que é muito respeitada no meio acadêmico e empresarial, é a Teoria de Necessidades Humanas. De acordo com essa teoria, que foi uma das primeiras a serem desenvolvidas e aplicadas ao mundo do trabalho, as necessidades humanas podem ser agrupadas em cinco níveis distintos.

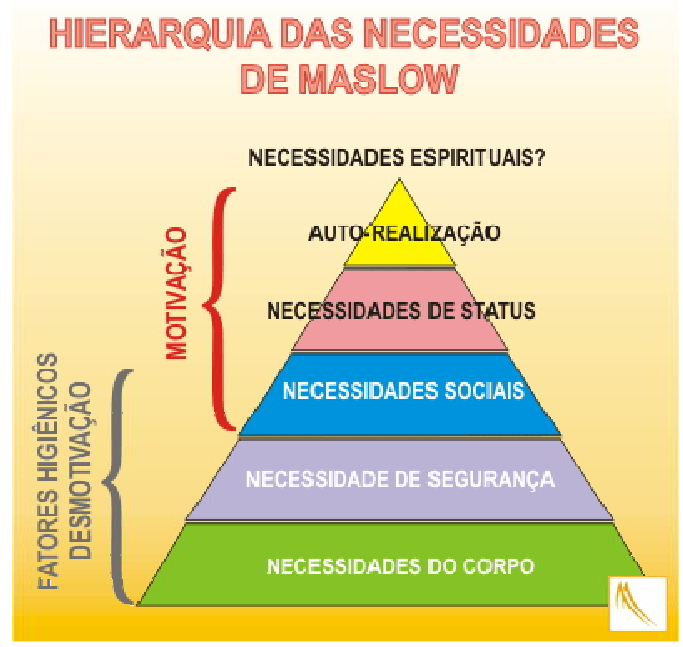

Figura 1. Hierarquia das Necessidades Humanas de Maslow Fonte: Faria (2008) 
Acerca da Hierarquia das Necessidades de Maslow, Faria (2008) explica que:

1. Necessidades fisiológicas: são as necessidades mais básicas, mais físicas (água, comida, ar, sexo, etc.) Uma vez satisfeitas, estas necessidades o ser humano abandona esta preocupação e passa a se preocupar com o atendimento de outras necessidades;

2. Necessidades de segurança: busca por abrigo, segurança, proteção, estabilidade e continuidade.

3. Necessidades sociais: o ser humano tem a necessidade de ser amado, querido por outros, de ser aceito por outros.

4. Necessidades de status ou de estima: o ser humano busca ser competente, alcançar objetivos, obter aprovação e ganhar reconhecimento. Há dois tipos de estima: a auto-estima e a hetero-estima. A auto-estima é derivada da proficiência e competência em ser a pessoa que se é, é gostar de si, é acreditar em si e dar valor a si próprio e a hetero-estima é o reconhecimento e a atenção que se recebe das outras pessoas.

5. Necessidade de auto-realização: o ser humano busca a sua realização como pessoa, a demonstração prática da realização permitida e alavancada pelo seu potencial único.

É preciso considerar que a motivação, devido à complexidade do indivíduo, envolve aspectos intra-psíquicos, culturais e fisiológicos, ou seja, não será apenas pelo controle de fatores culturais e sociais que a organização irá conseguir motivação dos trabalhadores.

Há urgência em compreender que a motivação no trabalho deve levar em consideração que o indivíduo age em conformidade com usas necessidades e expectativas intrínsecas e não somente em função de elementos fisiológicos e culturais que negligenciam seu aspecto emocional.

Neste sentido, o grande desafio dos dirigentes é conhecer as condições sob as quais as pessoas podem ser motivadas para executarem atividades dentro das organizações.

Neste contexto, é importante que os administradores estejam atentos para a relação existente entre motivação, satisfação e desempenho no trabalho, pois se o colaborador mantiver um bom nível de motivação, também terá maior probabilidade de exercer melhor sua função dentro da organização. Para tanto, é preciso que o 
próprio administrador se considere um ator sujeito às influências de seu ambiente e busque:

A valorização das pessoas pressupõe, acima de tudo, o reconhecimento de que eles são seres humanos e têm necessidade e anseios específicos, que precisam ser claramente entendidos e utilizados no desenvolvimento das estratégias, planos e práticas organizacionais, promovendo o alinhamento necessário para o sucesso da organização (ARAÚJO, 2008, p.7).

Assim, as organizações precisam ter uma visão clara que o ser humano é formado por características de personalidade únicas e complexas, e, que seu comportamento no trabalho é influenciado por diversos fatores.

\subsection{Clima Organizacional}

No mundo contemporâneo a compreensão do comportamento organizacional é de fundamental importância para a atuação dos administradores nas organizações. De acordo com Robbins (2002, p.6):

Comportamento organizacional é um campo de estudos que investiga o impacto que os indivíduos, grupos e a estrutura têm sobre o comportamento dentro das organizações, com o propósito de utilizar este conhecimento para promover a melhoria da eficácia organizacional.

Este novo paradigma surge como uma das respostas à globalização, pois as mudanças que ocorrem na sociedade afetam as habilidades humanas e tornamse um grande desafio para as organizações. Cada vez mais é imprescindível que as organizações consigam atender à diversidade humana dentro do ambiente de trabalho para que possa sobreviver, aumentando a sua qualidade de produtividade.

Robbins (2002, p. 14) afirma que a diversidade quando bem administrada, pode aumentar a criatividade e a inovação dentro das organizações, bem como melhorar as decisões tomadas, por trazer novas perspectivas em relação aos problemas.

Ao lidar com a diversidade, o ambiente de trabalho torna-se mais rico, pois conseqüentemente há uma grande variedade de pontos de vista, que se combinam gerando a inovação e maior produtividade. Uma das formas para administrar esta diversidade é por meio da gestão do Clima Organizacional. Assim as organizações monitoram constantemente as percepções das pessoas no seu ambiente de trabalho, conhecem o que funciona e o que não funciona na organização e tomam ações para melhorar o ambiente, a motivação e a qualidade de vida dos seus 
funcionários. O Clima Organizacional é ambiente humano dentro do qual as pessoas de uma organização fazem o seu trabalho ( LIMA \& ALBANO, 2002).

O Clima Organizacional é um fenômeno que resulta da interação de elementos da cultura, como preceitos, caráter e tecnologia. Decorre dos efeitos de cada um desses elementos culturais, valores, políticas, tradições, estilos gerenciais, comportamentos, expressões dos membros que estão envolvidos no processo. $O$ clima organizacional influencia direta e indiretamente os comportamentos, a motivação, a produtividade e a satisfação das pessoas que estão envolvidas com a organização (EDELA apud LIMA \& ALBANO, 2002).

De acordo com Payne \& Mansfiel (1973) apud Costa et al (2001), o Clima Organizacional é o elo conceitual de ligação entre o nível individual e o nível organizacional, no sentido de expressar a compatibilidade ou congruência das expectativas, valores e interesses individuais com as necessidades, valores e diretrizes formais da organização. Este conceito envolve uma visão mais ampla e flexível da influência ambiental sobre a motivação. Chiavenato (1999) afirma que o Clima Organizacional é:

É a qualidade ou propriedade do ambiente organizacional que é percebida ou experimentada pelos membros da organização e que influencia no seu comportamento. Refere-se ao ambiente interno existente entre as pessoas que convivem no meio organizacional e está relacionado com o grau de motivação de seus participantes.

Para Coda (1993), em Administração, o Clima Organizacional é o indicador do grau de satisfação dos membros de uma empresa, em relação a diferentes aspectos dos humanos, modelo de gestão, missão da empresa, processo de comunicação, valorização profissional e a identificação com a empresa. Souza (1978) define Clima Organizacional como "um fenômeno resultante da interação dos elementos da Cultura Organizacional, é uma conseqüência do peso de cada um dos elementos culturais e seu efeito sobre os outros dois."

Souza (1978) define Clima Organizacional como "um fenômeno resultante da interação dos elementos da Cultura Organizacional, é uma conseqüência do peso de cada um dos elementos culturais e seu efeito sobre os outros dois."

Conforme Luz (1996), clima organizacional é o reflexo do estado de espírito ou do ânimo das pessoas, que predomina numa organização em um determinado período, ou seja, é resultante da cultura das organizações; de seus aspectos positivos e negativos. Este autor afirma que o clima é afetado pelos conflitos e pelos 
fatores positivos e negativos que ocorrem no ambiente de trabalho, bem como fatores externos que ocorrem no contexto sócio-econômico e político, como, também, na vida particular dos funcionários. Ressalta ainda, a importância de destacar o fator tempo no conceito, uma vez que o clima organizacional é instável, conforme a influência que sofre de algumas variáveis.

É a partir das pesquisas de clima que as organizações conseguem melhorar as relações entre as pessoas no trabalho e elaborar projetos a partir das reivindicações dos próprios empregados, fazendo com que eles se sintam realmente parte integrante do negócio. O clima organizacional refere-se a uma "atmosfera" positiva ou negativa percebida pelos membros organizacionais, que funciona como um termômetro registrando os fenômenos resultantes da interação das dimensões formadoras da cultura.

De acordo com Lima \& Albano (2002, p.4):

O clima organizacional influencia e é influenciado pelo comportamento dos indivíduos na organização, no seu desempenho, motivação e satisfação no trabalho [...] Como mudanças na cultura organizacional são mais profundas, levam mais tempo para acontecer. Já o clima é mais fácil de ser percebido e apresentando uma natureza mais transitória, podendo ser administrado tanto a curto quanto a médio prazo.

Como cada uma das dimensões culturais é formada por diversos componentes, são várias as combinações possíveis entre eles, criando-se um ambiente de maior ou menor satisfação. O clima pode ser resultante das variáveis culturais. Quando estas são alteradas, ocasionam por sua vez, alterações no clima organizacional (HAMPTON, 1990). Dessa forma, o clima organizacional estabelece relações com a Cultura Organizacional, e mesmo que se refira a um momento específico da vida organizacional, exerce influência sobre a cultura e vice-versa, numa relação de retroalimentação. A interação desses elementos é complexa, simultânea e determina a satisfação ou insatisfação dos colaboradores para com a empresa (ROBBINS, 2002).

Diante do exposto o Clima Organizacional, no presente trabalho, é entendido como o conjunto de propriedades mensuráveis do ambiente de trabalho, percebido direta ou indiretamente pelos trabalhadores, e que influencia a motivação e o comportamento dos mesmos. 


\subsection{Comprometimento Organizacional e afetivo}

$\mathrm{Na}$ década de 60, Becker definiu comprometimento organizacional como o vínculo que o trabalhador desenvolve com a organização.

Para Regos et al (2007, p.1): "o comprometimento organizacional é o estado psicológico que caracteriza a ligação do indivíduo à organização, tendo implicações na sua decisão de nela continuar".

O comprometimento organizacional diz respeito também ao nível de identificação que o trabalhador tem em relação à organização na qual trabalha. Nos dias atuais, para que a organização obtenha vantagem competitiva e atinja seus objetivos e suas metas, é preciso que os trabalhadores esteja comprometidos e que ocorra um processo de identificação coma empresa (MULLER et al, 2005).

Para Mowday et al apud Souza et al (2008, p.2), o comprometimento organizacional é:

A força relacionada com a identificação e o envolvimento das pessoas com uma organização específica, expressa em três dimensões: fortes crenças e aceitação dos valores e objetivos da organização; desejo de exercer esforço em favor desta organização; e forte desejo de manter-se como um membro da organização.

Diversos estudos na área de administração desde a década de 70 demonstram que a importância do comprometimento organizacional para o sucesso da empresa. Autores como Senge (1998); (BASTOS, 1997); Bastos, Brandão e Pinho (1996); Moraes (1995) destacam que o comprometimento está relacionado ao sentimento de lealdade, de responsabilidade, de vínculo afetivo, envolvimento com as metas e objetivos da empresa ( MULLER et a, 2005).

Muller et al (2005) explicam que modelo de conceituação do comprometimento organizacional mundialmente aceito é o proposto por Meyer e Allen (1993). Na perspectiva destes autores existem três dimensões de comprometimento:

a) Affective Commitment, ou Comprometimento Afetivo: comprometimento como um envolvimento, onde ocorre identificação com os objetivos e valores da organização. Representa algo além da simples lealdade passiva, envolvendo uma relação ativa, na qual o indivíduo deseja dar algo de si para contribuir com o bem-estar da organização. Segundo Meyer e Allen, "Empregados com um forte comprometimento afetivo permanecem na organização porque eles querem (...)"; b) Continuance Commitment e que a literatura trata como Instrumental: comprometimento percebido como altos 
custos associados a deixar a organização. Segundo Meyer e Allen, "Empregados com (...) comprometimento instrumental permanecem porque eles precisam (...)"; c) Normative Commitment, ou Comprometimento Normativo: comprometimento como uma obrigação em permanecer na organização.(MULLER et al, 2005, p.3)

A abordagem Affective Commitment ou Comprometimento Afetivo defende a idéia de que o comprometimento organizacional vai além do sentimento de lealdade para com a empresa, envolvendo o sentimento ativo em busca do bem-estar da organização, ou seja, estão dispostos a se empenhar ao máximo, contribuindo de forma positiva para a organização (SOUZA et al, 2008; NAVES \& DELA COLETA, 2003).

Para Naves \& Dela Coleta (2003), esta abordagem afetiva do comprometimento organizacional se fundamenta nas teorias de Etzioni (1975) e de Mowday, Steers e Porter (1979).

Naves \& Dela Coleta (2003) afirmam que, para estes autores, estar comprometido com a organização significa:

A identificação e o envolvimento com a organização. $O$ indivíduo comprometido realiza um esforço considerável em prol da organização. Assim, eles o caracterizam como: (1) uma forte crença e aceitação dos objetivos e valores da organização; (2) uma tendência a manifestar um esforço considerável em favor da organização; e (3) a manifestação de um forte desejo de permanecer como membro da organização.

No âmbito organizacional, os indicadores afetivos são um dos principais fatores responsáveis pela efetividade e bom desempenho da equipe de trabalho.

Puntes -Palácios et al (201, p.6) afirmam que:

Com relação à efetividade das equipes de trabalho, é de longa data que autores como Hackman (1987) e Gladstein (1984) defendem que esta deve ser avaliada a partir de três parâmetros. O primeiro, e mais comumente utilizado, é composto pelos indicadores concretos, "duros", que contemplam a produção e os resultados quantificáveis de bens ou serviços. O segundo pressupõe a adoção de indicadores afetivos, como a satisfação e o comprometimento, os quais são considerados evidencias de bom funcionamento das equipes. $O$ terceiro refere-se à capacidade de sobrevivência da equipe. Em relação aos indicadores afetivos, Van der Vegt, Emans e Van de Vliert (1998) manifestam ser indicadores legítimos da efetividade, uma vez que focam nas relações afetivas dos membros das equipes, as quais são condições necessárias para a manutenção, sobrevivência e bom funcionamento dessas unidades de desempenho. 
A partir da análise empreendida, é possível concluir que o comprometimento afetivo do trabalhador diz respeito ao vínculo psicológico que estabelece com a organização na qual trabalha. Além disto, diz respeito também à identificação, bem como ao envolvimento emocional com a equipe de trabalho e com a organização.

\section{Métodos e Técnicas de Pesquisa}

\subsection{Caracterização da organização, setor ou área}

A empresa foi fundada em 1989, no município de São Paulo - SP. Atualmente possui 93 agências na capital, 42 na Grande São Paulo, 402 no interior de outros estados.

$\mathrm{Na}$ empresa, a Tecnologia de Informação utiliza o sistema de processamento informações real time, através de integração dos aplicativos e utilização de bases de dados Corporativos. A rede da empresa é automatizada, sendo que os sistemas aplicativos utilizam Bancos de Dados relacionais. Foi solicitado sigilo quanto à identificação da empresa.

\subsection{População e amostra ou participantes do estudo}

A amostra deste estudo é constituída por todos os integrantes do setor de informática da empresa participante do estudo. Os sujeitos foram participantes na modalidade censo, abrangendo a totalidade dos indivíduos do setor. 


\title{
3.3 Caracterização da amostra
}

A amostra se constitui de 20 indivíduos de ambos os sexos, com idade entre 20 a 35 anos. Os participantes da pesquisa atuam neste setor há mais de 3 anos.

\subsection{Método}

O método de pesquisa adotado para este estudo foi o da pesquisa survey, descritiva e pesquisa bibliográfica, com abordagem quantitativa, que permitiu uma análise sobre o comprometimento afetivo dos membros da equipe em estudo.

Para Oliveira (1997), método quantitativo é utilizado em pesquisas descritivas de natureza social, econômica, mercadológicas e de administração.

$\mathrm{Na}$ visão de Malhotra (2001, p.155), "a pesquisa quantitativa, procura quantificar os dados e aplicar alguma forma de análise estatística".

Segundo Terence \& Escrivão Filho (2006, p.3), "nos estudos organizacionais, a pesquisa quantitativa permite a mensuração de opiniões, reações, hábitos e atitudes em um universo, por meio de uma amostra que o represente estatisticamente".

Quanto á pesquisa survey, Pinsonneault e Kraemer (1993) apud Sacco,I \& Freita s9201, p.2) afirmam que:

\begin{abstract}
A pesquisa survey é um meio de captar informações sobre características, ações ou opiniões de um grande grupo de pessoas, referentes a uma população. Este método apresenta, entre outras, as seguintes características: a) o propósito é produzir descrições quantitativas de alguns aspectos da população estudada; é um método quantitativo; b) é o principal meio de coletar informações, através de perguntas pré-definidas e estruturadas; c) geralmente é coletada sobre uma parte da população.
\end{abstract}

A pesquisa descritiva é utilizada para descrever as características da população. Implica em observações, registros e análise do objeto que está sendo estudado. De acordo com Vieira (2002, p.3) "a pesquisa descritiva expõe as características de determinada população ou de determinado fenômeno, mas não 
tem o compromisso de explicar os fenômenos que descreve, embora sirva de base para tal explicação".

O levantamento bibliográfico visou buscar em fontes documentais (documentos impressos e arquivos eletrônicos) informações relevantes para a elaboração deste estudo. De acordo com Koche (1997, p.122), a pesquisa bibliográfica:

É a que se desenvolve tentando explicar um problema, utilizando o conhecimento disponível a partir das teorias publicadas em livros ou obras congêneres. O objetivo da pesquisa bibliográfica, portanto, é o de conhecer e analisar as principais contribuições teóricas existentes sobre um determinado tema ou problema, tornando-se um instrumento indispensável para qualquer tipo de pesquisa.

Posteriormente, foi realizada a leitura das fontes bibliográficas selecionadas, buscando subsídios para compreender e aprofundar o tema, relacionando-o às hipóteses inicialmente evocadas e o problema proposto.

\subsection{Caracterização dos instrumentos de pesquisa}

O instrumento utilizado para coleta dos dados foi o questionário Escala, Satisfação e Comprometimento de Equipes, de Puente-Palacios, um questionário com 14 questões fechadas, a fim de obter respostas claras e precisas, visando a caracterização da realidade em estudo.

O questionário foi subdividido em duas categorias:

\section{a) Equipe de trabalho à que você pertence.}

Nesta categoria foram apresentadas as seguintes questões:

1- Em relação aos membros da minha equipe de trabalho, eu sinto confiança que manteremos boas relações no futuro.

2- Tenho sentimentos positivos sobre a forma como trabalhamos juntos na minha equipe.

3- Estou satisfeito com a forma em que trabalhamos juntos na minha equipe.

4- Sinto-me bem a respeito do relacionamento que mantenho com os membros da minha equipe de trabalho.

5- Confio completamente nos membros da minha equipe. 


\section{b) Sentimentos em relação ao que você faz ou sente em relação à sua equipe.}

Nesta categoria foram apresentadas as seguintes questões:

1- Conversando com amigos, eu sempre me refiro a minha equipe de trabalho como uma grande unidade para a qual é ótimo trabalhar.

2- Eu julgo que os meus valores são muito similares aos valores defendidos pela equipe de trabalho a que pertenço.

3- Eu me sinto orgulhoso dizendo às pessoas que sou parte da minha equipe de trabalho. 4- A minha equipe de trabalho realmente inspira o melhor em mim, para o progresso no desempenho das minhas atividades.

5- Eu me sinto contente por ser parte desta equipe, comparando com outras que conheço.

6- Eu realmente me interesso pelo destino da equipe a que pertenço.

7- A minha equipe é a melhor de todas para se trabalhar.

8- Decidir trabalhar nesta equipe foi um erro de minha parte.

9- Eu sinto pouca lealdade para com a equipe em que trabalho.

Os participantes foram orientados para responder cada questão valorando sua resposta numa escala de 1 a 5 , sendo que :

1 para "Discordo totalmente"

2 para "Discordo parcialmente"

3 para "Nem concordo nem discordo"

4 para "Concordo parcialmente"

5 para " Concordo totalmente"

\subsection{Procedimentos de coleta e de análise de dados}

Para obter as informações necessárias para responder ao problema da pesquisa o procedimento utilizado para a coleta de dados foi uma reunião com os sujeitos selecionados, a fim de esclarecer os objetivos da pesquisa e obter dos 
mesmos o consentimento para a participação, respondendo o questionário. Após o esclarecimento, $100 \%$ dos sujeitos selecionados concordaram em participar da pesquisa.

A análise dos dados foi realizada com o objetivo de organizar os dados apresentados. Para a análise de dados foram elaborados gráficos para representar quantitativamente as respostas dos participantes. 


\section{RESULTADOS E DISCUSSÃO}

\section{1- Em relação aos membros da minha equipe de trabalho, eu sinto confiança que manteremos boas relações no futuro.}

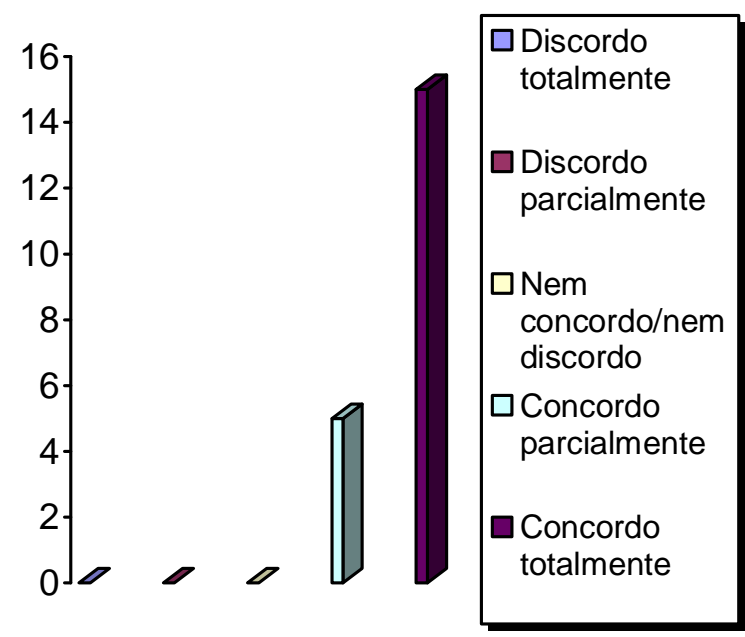

De acordo com os dados analisados no gráfico acima, pode-se verificar que 5 participantes concordam parcialmente que em relação aos membros da equipe sentem confiança que manterão boas relações no futuro. A maioria dos participantes (15) concorda totalmente em relação a esta questão. Nenhum dos participantes manifestou sentimento de discordância sobre a confiança em manter um bom relacionamento futuro com os membros de sua equipe.

Os resultados evidenciam que a relação de confiança entre os membros da equipe é positiva. Ao estabelecer relação de confiança a equipe de trabalho estará mais predisposta à participação e ao comprometimento. 
2- Tenho sentimentos positivos sobre a forma como trabalhamos juntos na minha equipe.

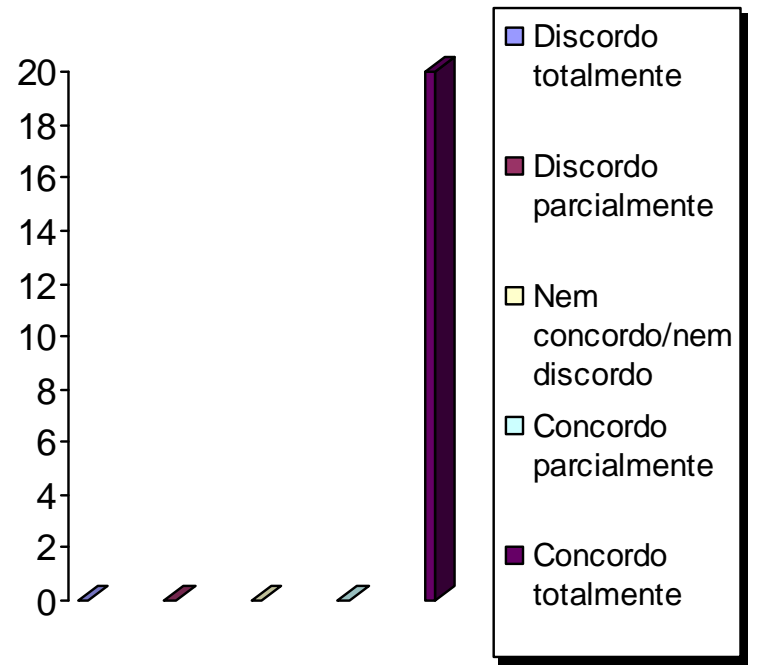

A análise dos dados do gráfico acima evidencia que todos os participantes possuem sentimentos positivos sobre a forma como trabalha em equipe. Pode-se verificar que nenhum dos participantes discorda que sentem sentimentos positivos em relação à forma como trabalham em equipe.

O sentimento positivo sobre a forma como trabalha em equipe, significa que também há respeito mútuo e sinergia para o alcance de metas. 


\section{3- Estou satisfeito com a forma em que trabalhamos juntos na minha equipe.}

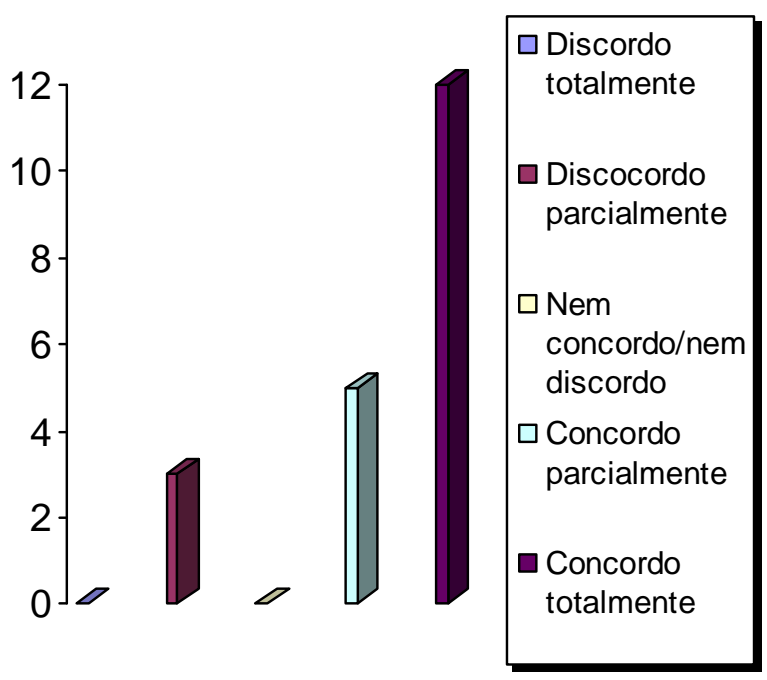

Pode-se verificar que com relação à satisfação em relação à forma como trabalham em equipe, 3 indivíduos manifestaram que concordam parcialmente que estão satisfeitos, sendo que 5 manifestaram que concordam parcialmente em relação ao seu nível de satisfação.

Do total (20), 12 manifestaram que concordam totalmente que estão satisfeitos em relação à forma sua equipe trabalha.

O contentamento manifestado com a forma como a equipe trabalha é um preditor da satisfação no ambiente de trabalho e possibilita o indivíduo construir competências na interação com outras pessoas. 


\section{4- Sinto-me bem a respeito do relacionamento que mantenho com os membros da minha equipe de trabalho.}

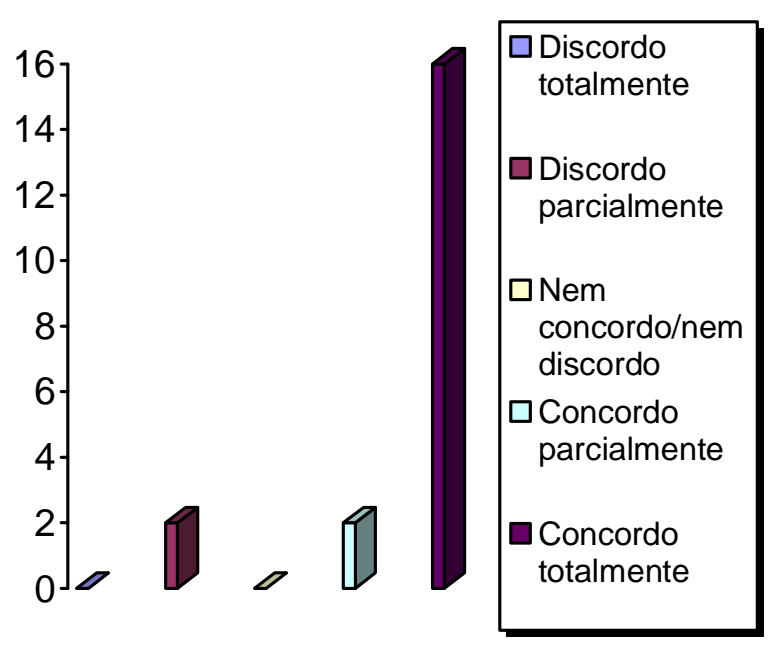

Ao verificar os resultados dos dados coletados no gráfico acima, constata-se que a minoria dos participantes, apenas 2 , discordam parcialmente que se sentem bem a respeito do relacionamento que mantém com os membros da sua.

Pode-se verificar 2 participantes concordam parcialmente que se sentem a respeito do relacionamento que mantém com os membros de sua equipe.

$\mathrm{Na}$ análise dos dados constata-se que 16 dos participantes concordam totalmente que se sentem bem em relação a respeito do relacionamento que mantêm com os membros de sua equipe.

O sentimento de satisfação que o trabalhador sente em relação ao relacionamento que mantém com sua equipe demonstra que existe qualidade no relacionamento associado a um grau de confiabilidade. 


\section{5- Confio completamente nos membros da minha equipe.}

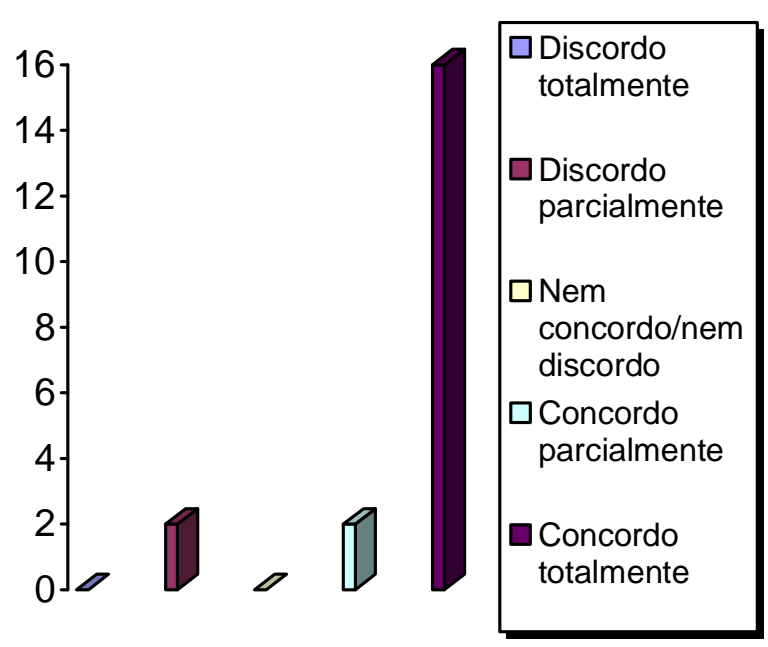

De acordo com dados coletados nesta pesquisa pode-se verificar que 2 dos participantes discordam parcialmente que confiam plenamente nos membros de sua equipe.Esta mesma proporção de participantes (2) foi encontrada para aqueles que concordam parcialmente que confiam completamente nos membros de sua equipe.

Os dados analisados evidenciam que a maioria dos participantes (16) concorda totalmente que confiam plenamente nos membros de sua equipe.

A relação de confiança entre os membros da equipe demonstra que existe comprometimento entre seus membros. A confiança entre os membros da equipe é um fator que influencia diretamente o desempenho nas tarefas organizacionais. 


\section{6- Conversando com amigos, eu sempre me refiro a minha equipe de trabalho como uma grande unidade para a qual é ótimo trabalhar.}

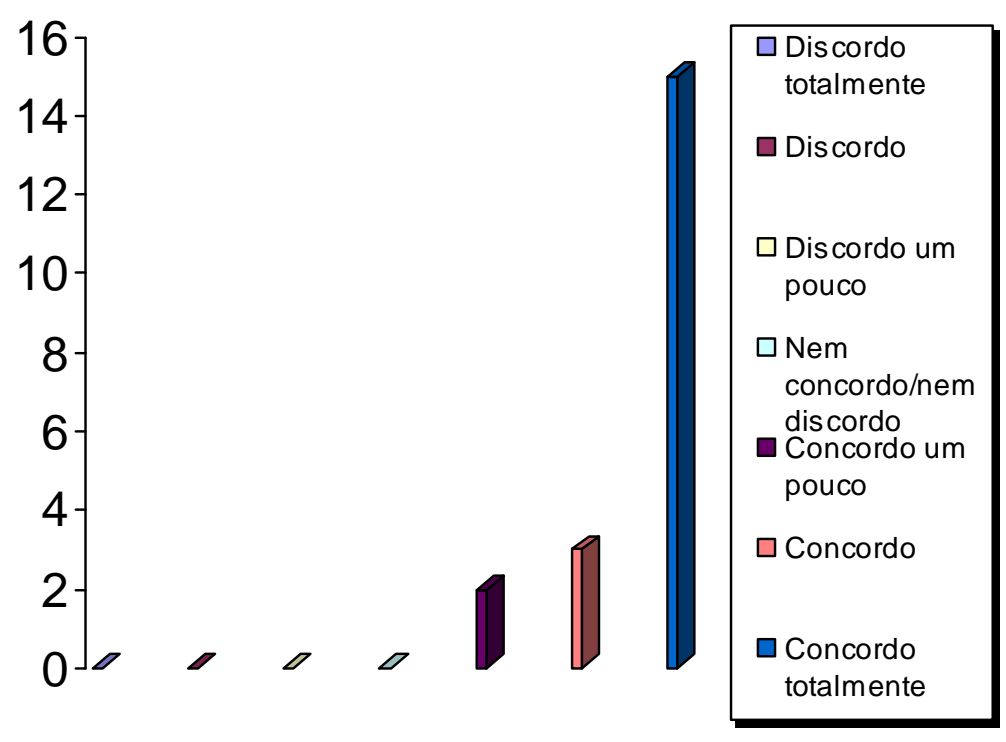

Ao analisar os dados do gráfico acima, pode-se verificar que 2 participantes concordaram um pouco que ao conversar com seus amigos sempre se refere à sua equipe de trabalho como uma grande unidade para a qual é ótimo trabalhar.Dos participantes, 3 manifestaram que concordam com a afirmativa proposta nesta questão.

Os resultados evidenciam que 15 participantes concordam totalmente ao afirmar sempre se refere à sua equipe de trabalho como uma grande unidade para a qual é ótimo trabalhar. Sempre que conversam com seus amigos. Nenhum resultado foi encontrado para as demais respostas.

O sentimento de satisfação em relação à equipe na qual trabalha revela que existe um processo de identificação com os valores e confiança que a sua equipe transmite. A predisposição para internalizar valores e crenças leva o indivíduo a querer compartilhar e também a se esforçar voluntariamente para cumprir metas propostas no ambiente de trabalho. 


\section{7- Eu julgo que os meus valores são muito similares aos valores defendidos pela equipe de trabalho a que pertenço.}

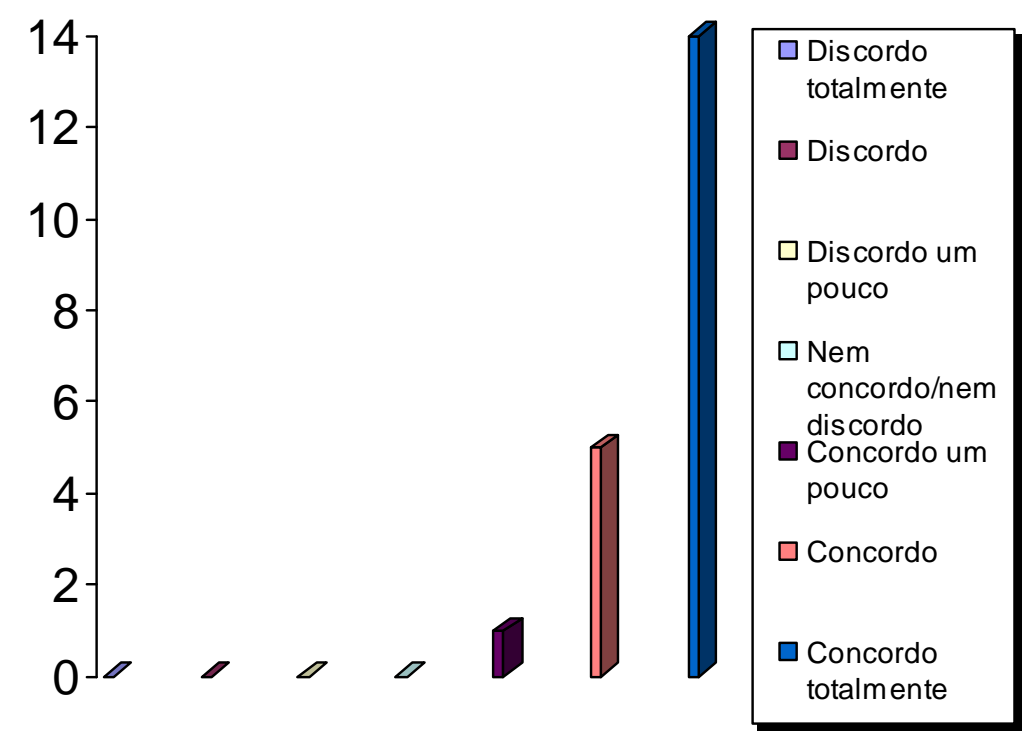

Em relação à similaridade de valores pessoais e os defendidos pela equipe de trabalho, esta pesquisa demonstra que somente 1 participante concorda um pouco com esta afirmativa, sendo que 5 participantes manifestaram que concordam.

Os 14 participantes disseram que concordam totalmente que seus valores são muito similares aos valores defendidos pela equipe de trabalho à qual pertencem. Nenhum resultado foi encontrado para as demais respostas.

Os dados analisados revelam que existe comprometimento afetivo entre os membros da equipe, pois existe a aceitação de valores, normas e objetivos da organização. 
8- Eu me sinto orgulhoso dizendo às pessoas que sou parte da minha equipe de trabalho.

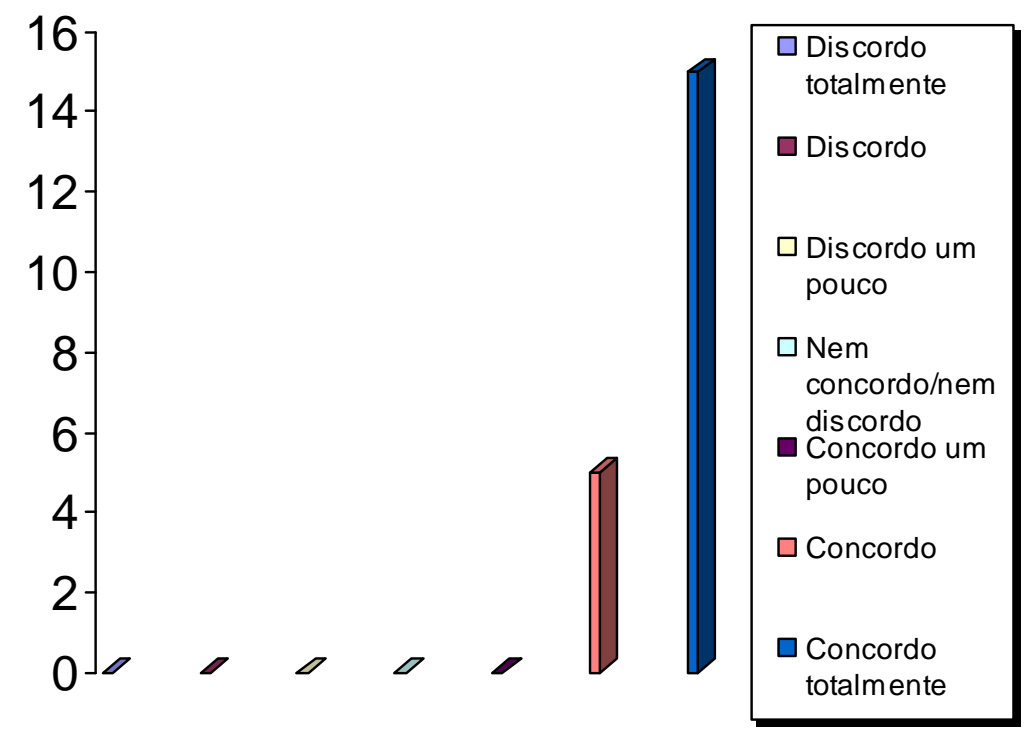

Os dados do gráfico acima evidenciam que 5 participantes da pesquisa concordam que sentem orgulho dizendo às pessoas que participam desta equipe de trabalho. A maioria dos participantes disse que concorda totalmente que sente orgulho da equipe de trabalho à qual pertence. Nenhum resultado foi encontrado para as demais respostas.

O orgulho que os indivíduos sentem em relação à sua equipe de trabalho demonstra o vínculo afetivo existe entre estes. Além disto, o sentimento de orgulho está relacionado aos sentimentos de confiança e de identificação com os valores e crenças transmitidos pela equipe e pela organização. 


\section{9- A minha equipe de trabalho realmente inspira o melhor em mim, para o progresso no desempenho das minhas atividades.}

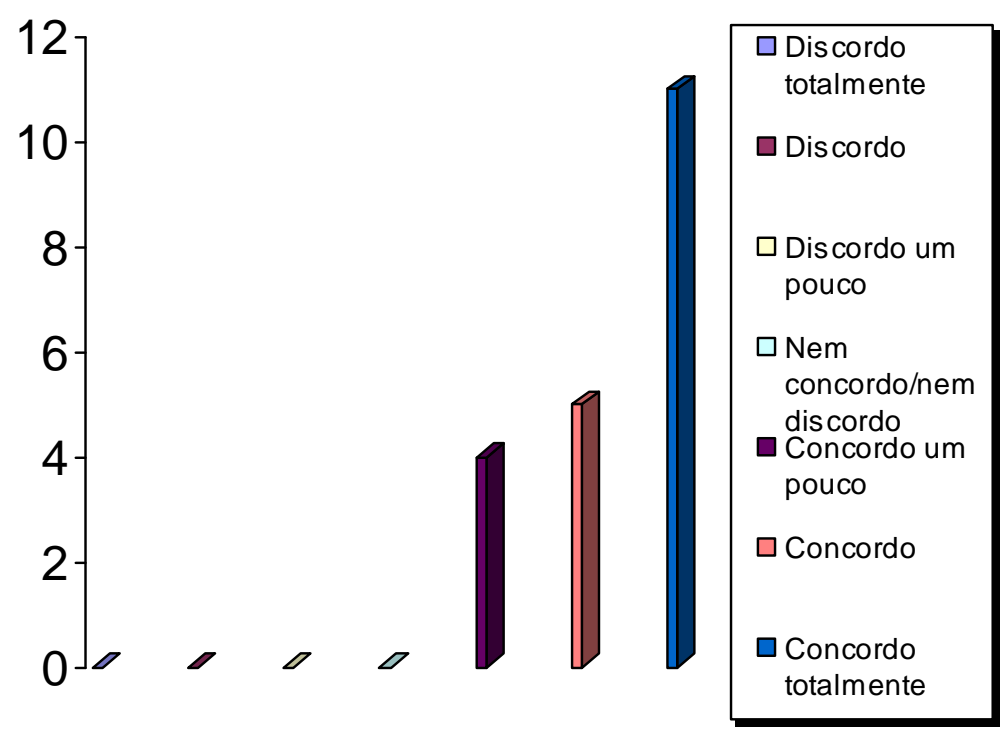

Pode-se constatar que 4 participantes concordam um pouco que a equipe de trabalho realmente inspira o melhor para o progresso no desempenho das atividades. Do total de participantes (20), 5 participantes expressaram que concordam que sua equipe de trabalho inspira o melhor e contribui para que haja progresso no desempenho das atividades. Em relação a esta questão, 11 participantes manifestaram que concordam totalmente que sua equipe de trabalho inspira o melhor e contribui para que haja progresso no desempenho das atividades. Nenhum resultado foi encontrado para as demais respostas.

Os dados analisados demonstram que o indivíduo sente bem-estar em participar de sua equipe de trabalho e principalmente que os comportamentos e atitudes de sua equipe são motivadores e incentivadores para o seu desempenho no ambiente organizacional. 
10- Eu me sinto contente por ser parte desta equipe, comparando com outras que conheço.

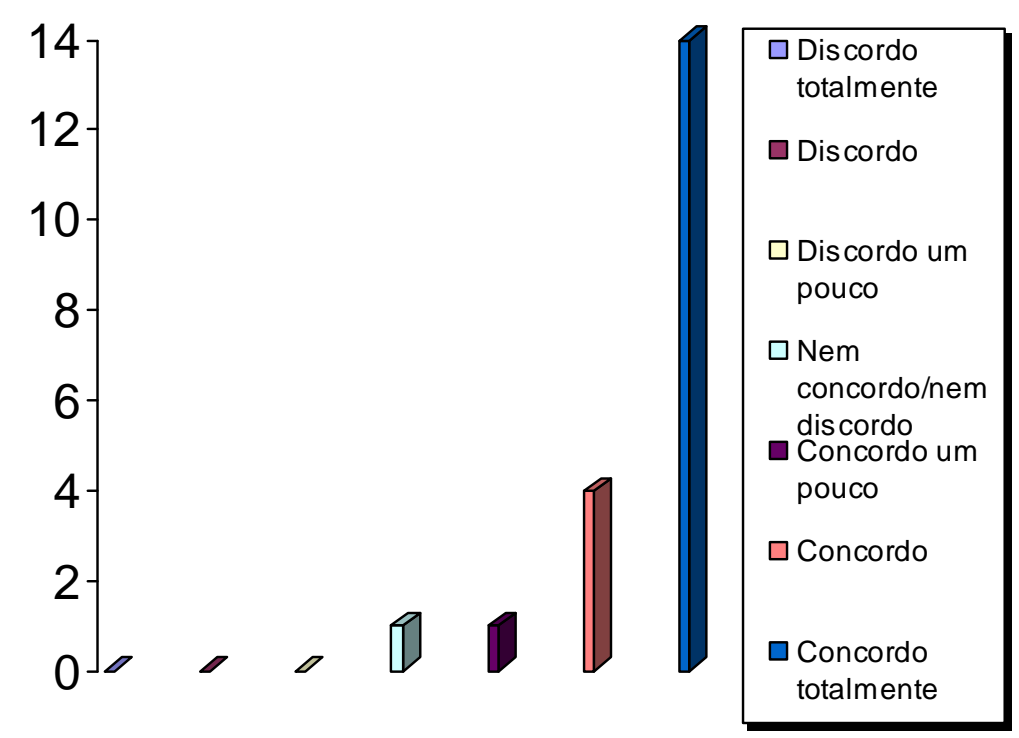

Dos dados analisados verifica-se que foi encontrada a mesma proporção entre aqueles que nem concordam e nem discordam (1) e aqueles que concordam um pouco (1) com esta afirmativa. Dos participantes, 4 manifestaram que concordam que se sentem contentes por ser parte desta equipe, comparando com outras que conhece.

A maioria dos participantes disse que concorda totalmente que se sente contente por fazer parte desta equipe, comparando com outras que conhecem. Nenhum resultado foi encontrado para as demais respostas.

Os dados analisados sugerem que os comportamentos e atitudes dos membros da equipe são eficazes e são motivadores para manter a coesão e o sentimento de contentamento entre os membros do grupo. 
11- Eu realmente me interesso pelo destino da equipe a que pertenço.

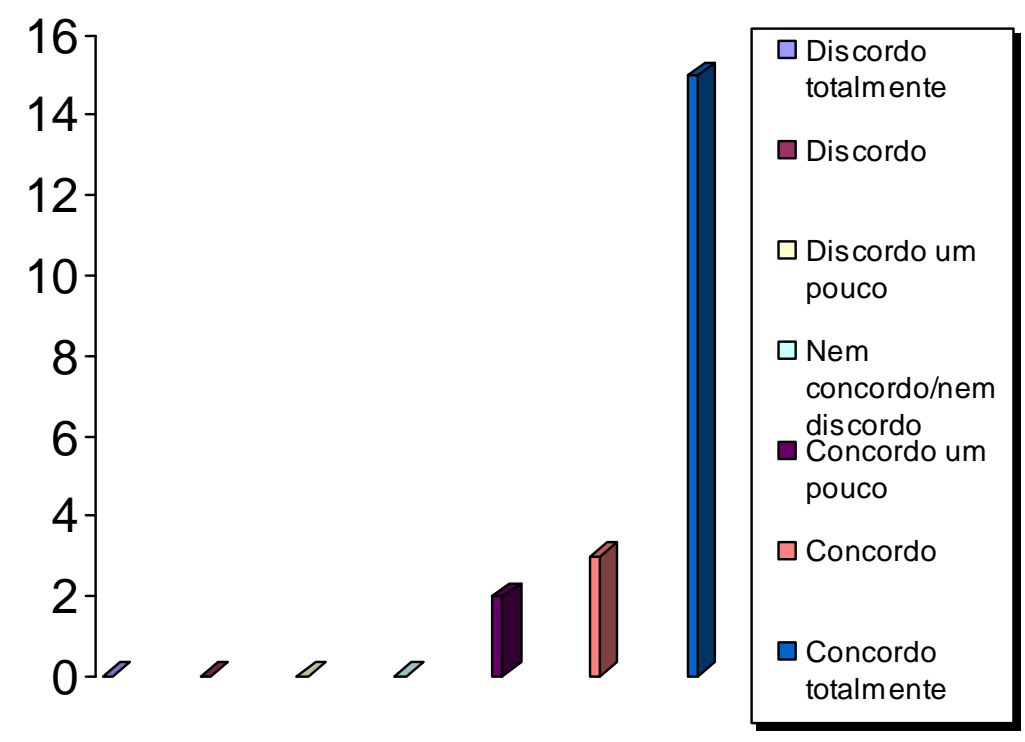

Ao analisar os resultados dos dados coletados, pode-se verificar que 2 participantes da pesquisa concordam um pouco sobre seu interesse pelo destino da equipe à qual pertencem Em relação a esta questão, 3 manifestaram que concordam. Ficou evidenciado que 15 dos participantes da pesquisa responderam que concordam totalmente que se sentem interessados pelo destino da equipe à qual pertencem. Nenhum resultado foi encontrado para as demais respostas.

$O$ interesse pelo destino da equipe de trabalho manifesta 0 comprometimento afetivo para com esta, originado do vínculo que estabeleceu, no qual há aceitação de valores e crenças do grupo e também o desejo voluntário de partilhar idéias e valores. 
12- A minha equipe é a melhor de todas para se trabalhar.

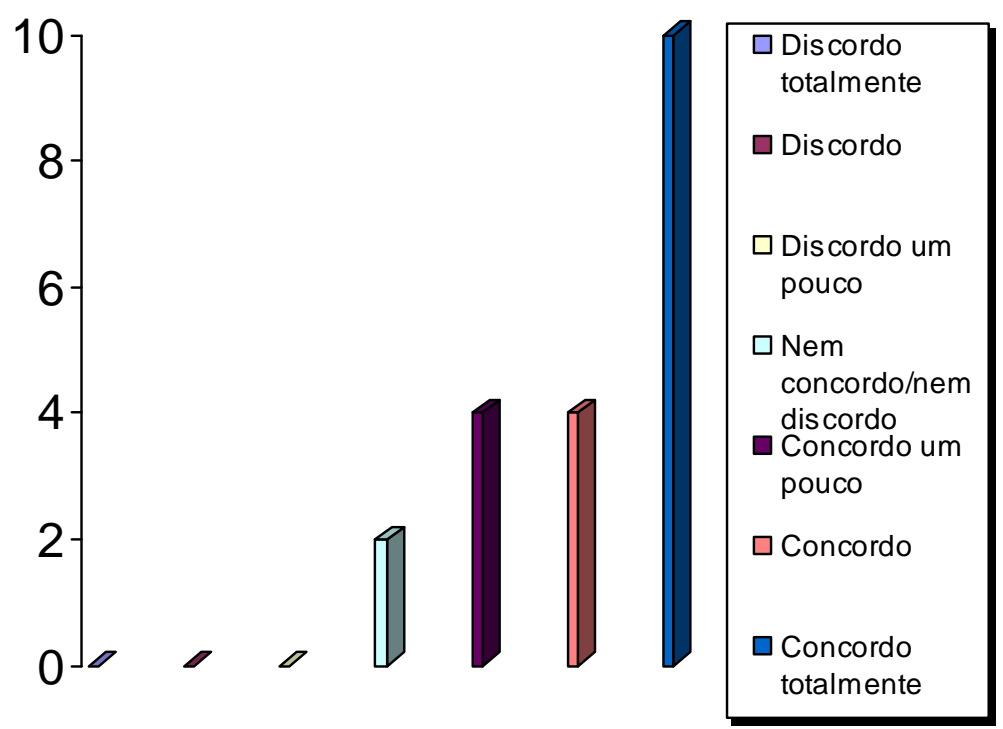

Com relação à questão se minha equipe é a melhor de todas para se trabalhar, constata-se que 2 participantes nem concordam e nem discordam, sendo que 4 concordam um pouco. Aqueles que concordam, verifica-se que são 4.

Dos participantes nesta pesquisa, 10 concordam totalmente que a sua equipe é a melhor para se trabalhar. Nenhum resultado foi encontrado para as demais respostas.

Ao considerar que a equipe na qual trabalha é a melhor, o indivíduo sente bem-estar, apoio e força para realizar suas tarefas cotidianas. Os resultados sugerem que a equipe trabalha em harmonia e buscam unir esforços para atingir seus objetivos. 
13-Decidir trabalhar nesta equipe foi um erro de minha parte.

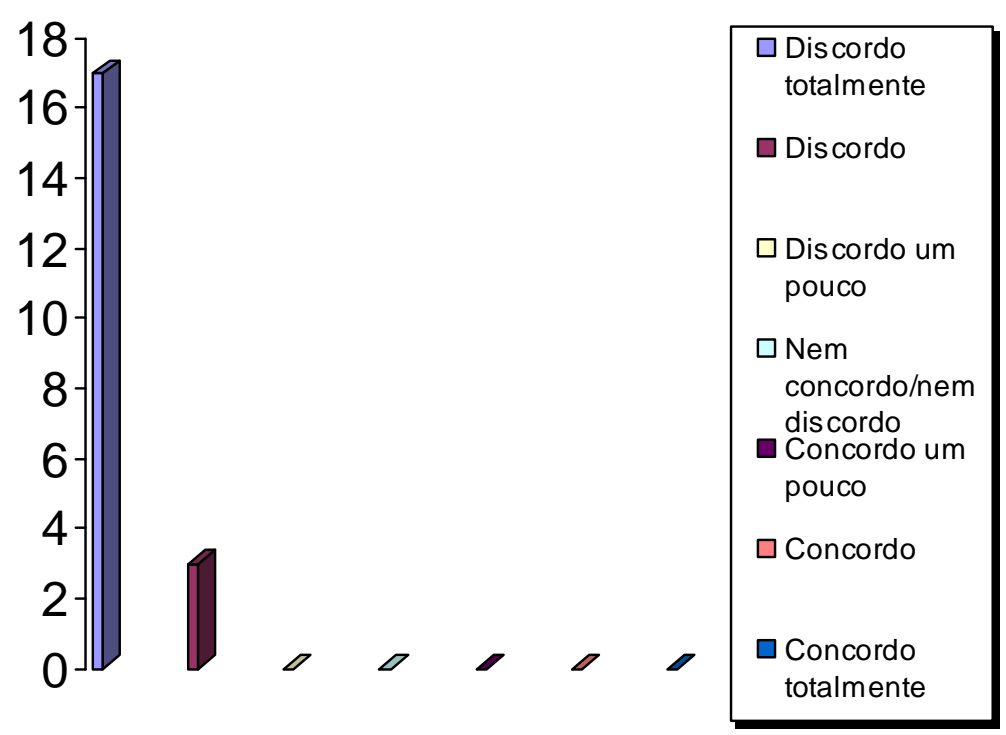

$\mathrm{Na}$ análise dos dados deste estudo pode-se observar que a maioria dois participantes discordam totalmente de que a decisão de trabalhar nesta equipe foi um erro. Em relação a esta questão, a minoria (3) concordou um pouco que a decisão de trabalhar nesta equipe foi um erro. Nenhum resultado foi encontrado para as demais respostas.

Os dados analisados demonstram que os indivíduos sentem grande satisfação em pertencer a esta equipe. Este sentimento de pertença ao grupo expressa o vínculo afetivo que estabeleceu com os membros da equipe. Demonstra também que existe um sinergismo entre as pessoas que buscam o melhor desempenho em sua atuação profissional. 
14-Eu sinto pouca lealdade para com a equipe em que trabalho.

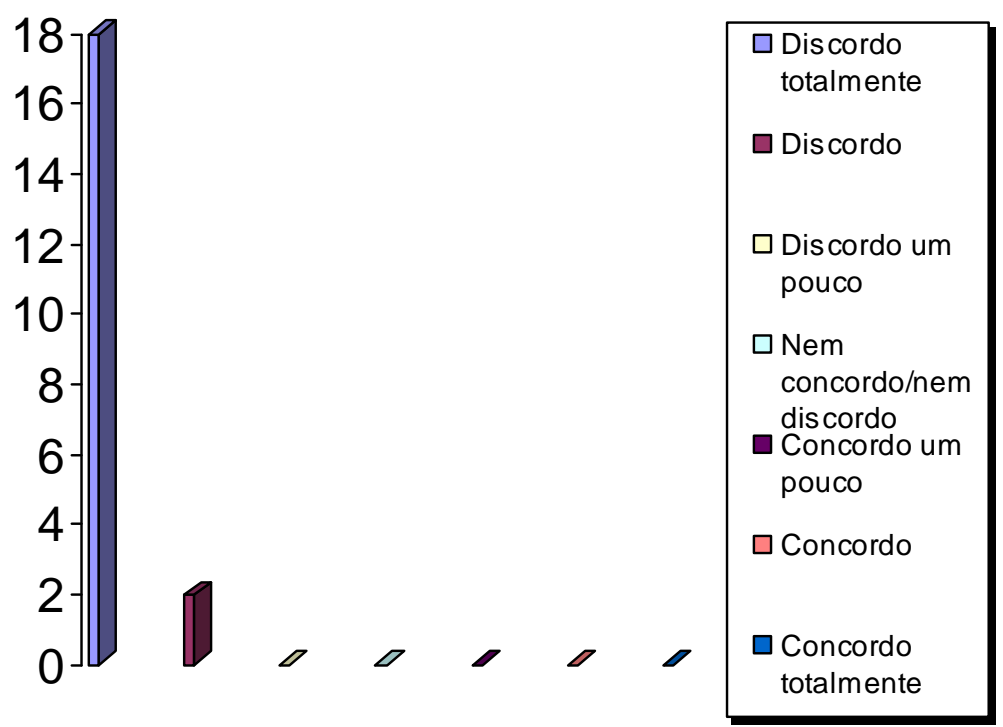

Os dados do gráfico acima evidenciam que 2 participantes concordam um pouco que sentem pouca lealdade em relação à equipe em que trabalham. Dos participantes, a maioria (18) manifestou que discorda totalmente que sentem pouca lealdade em relação à equipe em que trabalham. Nenhum resultado foi encontrado para as demais respostas.

O sentimento de lealdade é um indicador de que a equipe apresenta comprometimento afetivo, uma vez que a lealdade é baseada em valores e nas interações de forma ética. 


\title{
5 DISCUSSÃO
}

Analisando os resultados obtidos neste estudo observa-se que em relação aos membros da equipe de trabalho a maioria dos participantes (15) concordam totalmente que sentem confiança que manterão boas relações no futuro. Contudo existe uma parcela de participantes que concorda parcialmente que em relação a esta questão.

A análise dos dados coletados evidencia que todos os participantes possuem sentimentos positivos sobre a forma como trabalha em equipe, proporcionando melhor coesão entre os membros do grupo. Os dados evidenciam que existe confiança e compromisso entre os indivíduos que fazem parte desta equipe.

De acordo com Laves \& Mello (2006), as organizações contemporâneas exigem grupos de trabalho coesos, pautados em intensa comunicação, confiança e credibilidade, conhecimentos compartilhados, com senso de solidariedade para que o trabalho seja realizado com eficácia.

Pode-se verificar que com relação à satisfação em relação à forma como trabalham em equipe, que a maioria dos participantes (12) manifestou que concordam totalmente que estão satisfeitos em relação à forma sua equipe, sendo que os demais concordam parcialmente. Os resultados demonstram que os trabalhadores do setor de informática apresentam disposição e vontade de trabalhar produtivamente, indicando assim seu estado de motivação e também que são valorizados pela empresa onde trabalham.

Nas palavras de Gondim \& Silva (2004, p.165):

\begin{abstract}
Quando o conhecimento do trabalhador é ignorado, a tendência é que ele se sinta desmotivado e resistente para eventuais mudanças que possam estar sendo implementadas. Isso porque não se pode esperar muita motivação de trabalhadores cuja opinião é pouco valorizada e que estão cientes de que as decisões que irão influenciar as suas vidas profissional e pessoal serão tomadas por pessoas que desconhecem suas necessidades, expectativas e projetos de vida de modo geral.
\end{abstract}

Dentro da organização o indivíduo, tanto colaborador quanto administrador, quando valorizado tende a desenvolver forças motivacionais como produto do ambiente no qual está inserido. Existem forças motivacionais dominantes no indivíduo e que demonstram a importância da motivação para que a organização obtenha sucesso no mundo dos negócios. Novaes ( 2007, p.1) explica que: 
O desafio das organizações reside na necessidade de compreender a dinâmica dos processos internos que movem as pessoas, por meio da adoção de práticas que corroborem o sentido de pertença, a satisfação das pessoas e conseqüentemente, o sucesso e o fortalecimento da imagem da organização. (Novaes, 2007, p. 1)

Assim sendo, é preciso que as organizações busquem identificar os fatores que atuam como motivadores do comportamento humano no trabalho, no ambiente em que atuam, tendo em vista atuar de modo efetivo para o pleno desenvolvimento deste, considerando a complexidade do ser humano.

Ao verificar os resultados dos dados coletados no gráfico acima, constata-se que a maioria dos participantes, 16 dos participantes concordam totalmente que se sentem bem em relação a respeito do relacionamento que mantêm com os membros de sua equipe.

Para Campos et al (2009, p.2):

A satisfação é responsável pelo crescimento e desenvolvimento pessoal e organizacional e ocorre quando o profissional não é motivado [...] a satisfação das necessidades na situação de trabalho é de fundamental importância para melhorar a sua produtividade e está diretamente ligada à motivação.

Quanto à avaliação sobre a confiança nos membros da equipe, esta pesquisa demonstrou que maioria dos participantes (16) concorda totalmente que confiam plenamente nos membros de sua equipe. De acordo com Nakayama et al (2007) confiança entre os membros de uma equipe facilita a aprendizagem dentro e fora da equipe. Este sentimento de confiança é fundamental para que os membros da equipe unam esforços para atingir seus objetivos comuns dentro da organização. Além disto, demonstra que existe comprometimento afetivo, pois a confiança é um dos sentimentos que é a base do relacionamento interpessoal com afetividade.

Os resultados evidenciam que 15 sujeitos da pesquisa concordam totalmente ao afirmar sempre se refere à sua equipe de trabalho como uma grande unidade para a qual é ótimo trabalhar sempre que conversam com seus amigos. Verifica-se, portanto, que as relações entre os membros desta equipe são consideradas boas, indicando que há um bom nível de comunicação entre estes.

Araújo et al (2006) explicam que a comunicação é um instrumento de relacionamento interno entre os profissionais e para o fluxo de atividades.

Em relação à similaridade de valores pessoais e os defendidos pela equipe de trabalho, esta pesquisa demonstra 14 participantes concordam totalmente que seus valores são muito similares aos valores defendidos pela equipe de trabalho à 
qual pertencem. Estes resultados demonstram que o clima entre os membros da equipe é satisfatório. Para Puente- Palácios et al (2010, p.3):

\begin{abstract}
O clima apresenta papel central na explicação de comportamentos e desempenhos, no contexto das equipes 0 impacto das relações estabelecidas entre seus membros e as regras de comportamento e desempenho (clima) podem ser elementos que facilitam ou dificultam o alcance das metas propostas. Esta afirmação torna-se adequada, principalmente, se considerado que as equipes se caracterizam pela presença de relações complexas de interação e dependência existentes entre seus membros.
\end{abstract}

Os dados analisados evidenciam que a maioria dos participantes sente orgulho da equipe de trabalho à qual pertence e que sua equipe de trabalho inspira o melhor e contribui para que haja progresso no desempenho das atividades. Além disto, pode-se verificar que os participantes se sentem contentes por fazer parte desta equipe, comparando com outras que conhecem. Há também sentimento de confiança entre os membros da equipe, levando à atuação com esforços conjunto para atingir as metas organizacionais, sugerindo a construção de uma equipe de alta produtividade.

Para Wellins et al apud Deher et al (2006, p.4):

As equipes altamente eficazes ou de alto desempenho, são compostas por grupos de indivíduos comprometidos que confiam uns nos outros; tem um claro sentido de propósito em relação ao seu trabalho; são eficazes comunicadores dentro e fora da equipe; certificam-se que todos na equipe estão envolvidos nas decisões do grupo; e seguem um processo que os permitem planejar, tomar decisões e garantir a qualidade de seu trabalho.

Os resultados obtidos coma realização da presente pesquisa evidenciam que os participantes sentem interessados pelo destino da equipe à qual pertencem $\mathrm{e}$ que consideram que a sua equipe é a melhor para se trabalhar. Foi constatado que nenhum participante considerou um erro a decisão de trabalhar nesta equipe.

Com base nestes dados, pode-se inferir que as relações interpessoais mantidas entre os membros da equipe têm nível satisfatório e que isto interfere diretamente em seu desempenho, demonstrando que existe o vínculo afetivo entre os membros da equipe.

Para Puente - Palácios et al (2010, p.6) " ao conhecermos mais sobre o comprometimento das pessoas e o que as leva ao estabelecimento desses vínculos, mais poderemos predizer os seus comportamentos e desempenhos". 


\section{CONCLUSÕES E RECOMENDAÇÕES}

O objetivo deste estudo foi analisar o comprometimento afetivo da equipe de trabalhadores terceirizados em setor de informática de empresa uma bancária.

Com a realização deste estudo foi possível averiguar a forma como esses trabalhadores percebem a sua relação com a equipe de trabalho.

Constatou-se que nesta equipe de trabalho os membros partilham os sentimentos de confiança, lealdade e orgulho.

De acordo com a literatura analisada, confiança, lealdade e orgulho são sentimentos indicadores da existência de harmonia entre a equipe, revelando também que existe um compartilhamento de crenças e de valores, que são a base do comprometimento afetivo e organizacional.

A pesquisa demonstrou que os membros desta equipe de trabalho sentem satisfação em fazer parte dela e revelou que o comprometimento afetivo predominou entre estes profissionais.

Partindo da idéia de que o comprometimento afetivo e organizacional é fundamental para que haja bom desempenho nas tarefas organizacionais, este estudo recomenda que as organizações estimulem o desenvolvimento do comprometimento afetivo entre os trabalhadores.

O presente estudo propõe que novas pesquisas sejam realizadas no âmbito das organizações a fim de conhecer os sentimentos dos trabalhadores em relação à sua equipe, visando enriquecer os conhecimentos nesta área do conhecimento e trazendo contributo para a aplicação prática no dia-a-dia das organizações. 


\section{REFERÊNCIAS}

ALMEIDA, Gustavo de Oliveira et al. Justiça Organizacional - Relações com a Ineficácia Profissional, Comprometimento Afetivo e Auto Percepção de Saúde Geral, 2005.Disponível em $\quad<$ http://www.ead.fea.usp.br/Semead/9semead/resultado_semead/trabalhosPDF/341.p df>Acesso em 3 de março de 2011.

ALVES, Marília; MELLO, Renata Avelar de. Trabalho em equipe entre profissionais da enfermagem em um centro de terapia intensiva. Ciência, Cuidado e Saúde Maringá, v. 5, n. 3, p. 299-308, set./dez. 2006.

ANDRADE, Antonio Rodrigues de. O fluxo de informação e a eficiência operacional das organizações um ensaio sob a perspectiva da tecnologia da informação, 2005. Disponível em :< www.aedb.br/.../46_0\%20FLUXO\%20DE\%20INFORMACAO\%20E\%20A\%20EFICI.. . Acesso em 5 de março de2011.

ARAUJO, Eciene Cassandra da Costa. A comunicação de equipes multidisciplinares - um estudo sobre a A.A.C.D. em Uberlândia, MG. UNESCOM - Congresso Multidisciplinar de Comunicação para o Desenvolvimento Regional São Bernardo do Campo - SP. Brasil - 9 a 11 de outubro de 2006 - Universidade Metodista de São Paulo. Disponível em : http://encipecom.metodista.br/mediawiki/images/7/76/GT_3_4_e_5_-_COMSAuDE_02-_A_comunicacao_de_equipes-_Ecien_.pdf>Acesso em 3 de março de 2011

BERGAMINI, Cecília Whitaker. Motivação nas organizações. $4^{a}$ ed. São Paulo: Atlas, 1997.

BEUREN, Ilse Maria (Org.). Como elaborar trabalhos monográficos em contabilidade: teoria e prática. 3. ed. São Paulo: Atlas 2006.

BORGES, Erivan Ferreira; MEDEIROS, Carlos Alberto Freire. comprometimento afetivo e afiliativo: uma abordagem comparativa entre os enfoques no contexto profissional dos contadores atuantes na cidade de Natal/RN. Revista de Contabilidade do Mestrado em Ciências Contábeis da UERJ, Rio de Janeiro, v.12, n.3, p.1, set./dez., 2007

BORGES, Fabricio Quadros. A evolução da administração no ambiente da globalização. Adcontar, Belém, v. 2, no 1, p. 7-10, maio 2001.

CAMPOS R .M. et al. Satisfação profissional da equipe de enfermagem do SAMU/Natal. Rev. Eletr. Enf. 2009;11(3):647-57.

CHIAVENATO, I. Gestão de Pessoas: O novo papel dos recursos humanos nas organizações. $6^{\mathrm{a}}$ tiragem. Rio de Janeiro: Campus, 1999. 
CODA, R. Estudo sobre clima organizacional traz contribuição para aperfeiçoamento de pesquisa na área de $\mathrm{RH}$. In: Boletim Administração em Pauta, suplemento da Revista de Administração, São Paulo. IA-USP, n. 75, dez., 1993

CORREA, André Luiz. A internacionalização da indústria brasileira e seus impactos sobre os coeficientes de pass-through no Brasil no período 1996-2001,2004. Disponível em

$:<$ http://www.anpec.org.br/encontro2004/artigos/A04A105.pdf>acesso em 4 de janeiro de 2011.

COSTA, Camila Furlan da et al. Clima Organizacional: um estudo comparativo entre modelos de avaliação de clima em instituições de ensino superior. Associação educacional Dom Bosco, 2001.Disponível em http://www.aedb.br/seget/artigos06/745 Artigo\%20Clima\%20organizacional.pdf $>$ Ace sso em 4 de março de 2011.

COUTINHO Luana da Silva, et al. Pessoas: principal fonte de vantagem competitiva organizacional, 2008.Disponível em < http://www.aedb.br/seget/artigos09/102 Pessoas Principal Fonte de vantagem Co mpetitiva.pdf $>$ Acesso em 4 de fevereiro de 2011.

DREHER, Marialva Tomio et al. Equipes de Alta Performance e Obtenção de Resultados: Avaliação de Desempenho na Empresa de Intercâmbio Cl em

Blumenau - $\quad$ SC 2005.Disponível em $<$ http://www.aedb.br/seget/artigos08/304_Artigo\%20Seget_corrigido.pdf>Acesso em 3 de março de 2011.

FARIA, Carlos Alberto de. As nossas necessidades e os nossos desejos.Disponível em :< http://www.merkatus.com.br>..Acesso em 4 março de 2011.

FIORELLI, J. O. Psicologia para administradores. São Paulo: Atlas, 2004. p. 118132.

GONDIM, Sônia Maria Guedes; SILVA, Narbal. Motivação no trabalho in Psicologia, organizações e trabalho. Porto Alegre: Artmed, 2004.

HAMPTON, David R.Administração:comportamento organizacional, São Paulo: McGraw-Hill, 1990.

LIMA, Súsi M. Barcelos ALBANO; Adriana Gaffrée Burns. Um estudo sobre clima e cultura organizacional na concepção de diferentes.. Rev. CCEI - URCAMP, v.6, n.10, p. 33-40 - ago., 200233

LIMA, Claudinete Salvatto; URBINA, Lígia Maria Soto. Eficiência competitiva através de investimentos em capital humano, XXII Encontro Nacional de Engenharia de Produção Curitiba - PR, outubro de 2002. Disponível em: <http://www.abepro.org.br/biblioteca/ENEGEP2002_TR15_0828.pdf>. Acesso em 25 de de fevereiro de 2011. 
LUZ, R. S, Conhecendo o clima organizacional, Revista treinamento e Desenvolvimento, v. 4. №. 41, maio, p 14-15, S. Paulo,1996.

MALHOTRA, N. K. Pesquisa de Marketing: uma orientação aplicada. 3. ed. Porto Alegre: Bookman, 2001.

MEYER, Paola Braga. Motivação organizacional, 2007. Disponível em:< http://senacrs.spaceblog.com.br/17052/MOTIVACAO-ORGANIZACIONAL/> Acesso em 11 de março de 2011.

MÜLLER, Michele et al. Comprometimento organizacional: um estudo de caso no supermercado "beta" organizational commitment: a case study in "beta" supermarket . Revista Gestão Industrial. v. 01, n. 04 : pp. 511-518, 2005.

NAKAYAMA, Marina Keiko et al. Construção da relação entre confiança e as cinco disciplinas de Senge na gestão de equipes virtuais e semi- virtuais.CINTED-UFRGS-.Novas Tecnologias na educação.V. 5 № 2, Dezembro, 2007.Disponível em :< http://www.cinted.ufrgs.br/ciclo10/artigos/3cMarina.pdf>Acesso em 2 de março de 2011.

NAVES, Évora Mandim Ribeiro; DELA COLETA, Marília Ferreira. Cultura e Comprometimento Organizacional em Empresas Hoteleiras. RAC, Edição Especial 2003: 205-222

NOVAES. Marília Vieira. A importância da motivação para o sucesso das equipes no contexto organizacional, Revista Eletrônica de Psicologia, Ano I Número 1,Julho de 2007. Disponível

em:< http://www.pesquisapsicologica.pro.br/pub01/marilia.htm\#SUMÁRIO>. Acesso em 11 de agosto de 2009.

OLIVEIRA, S. L. Tratado de metodologia científica: PROJETOS DE PESQUISAS, TGI, TCC, monografias, dissertações e teses. São Paulo: Pioneira, 1997.

OLIVEIRA, Elisângela Magela. Transformações no mundo do trabalho, da revolução industrial aos nossos dias. Caminhos de geografia - Caminhos de Geografia 6(11)84-96, $\quad$ Fev/2004.Disponível em : http://www.ig.ufu.br/revista/volume11/artigo06_vol11.pdf>Acesso em 2 de janeiro de 2011.

PUENTE-PALACIOS, Katia; VIEIRA, Rafaella de Andrade; FREIRE, Raphael Andrade Nunes. o impacto do clima no comprometimento afetivo em equipes de trabalho. Aval. psicol., Porto Alegre, v. 9, n. 2, ago. 2010.

ROBBINS, S.P. Comportamento organizacional, 9ª ed., Rio de Janeiro: LTC, 2002.

SACCOL, A. Z. FREITAS, H.; Pesquisa Survey: um estudo comparativo entre Brasil, França e Estados Unidos sobre a influência cultural e da experiência decisória sobre a percepção do processo decisório individual. Revista Quanti \& Quali. 2010. Disponível em:, http://www.quantiquali.com.br/revista/index.php?do=04. >Acvesso 
em 4 de março de 2011.

SOUZA, Wilson Rodrigues de et al. O Comprometimento no Trabalho em um Ambiente Modificado: um Estudo De Caso no Ramo Metalúrgico. Revista Gestão \& Tecnologia, Pedro Leopoldo, v. 8, n. 2, p. 1-18, jul./ago. 2008.

SOUZA, E. L. P. Clima e Cultura Organizacionais: como se manifestam e como se manejam. Porto Alegre:Edgar Blücher, 1978.

TAMAYO, Alvaro; PASCHOAL, Tatiane. A relação da motivação para o trabalho com as metas do trabalhador. Rev. adm. contemp., Curitiba, v. 7, n. 4, Dec. 2003 . Disponível em:<www.scielo.br/scielo.php?script=sci_arttext\&pid=S141565552003000400003\&lng=en\&nrm=iso $>$.Acesso em 3 de janeiro de 2011.

TERENCE, Ana Cláudia Fernandes; ESCRIVÃO FILHO, Edmundo. Abordagem quantitativa, qualitativa e a utilização da pesquisa-ação nos estudos organizacionais. XXVI ENEGEP - Fortaleza, CE, Brasil, 9 a 11 de Outubro de 2006 ENEGEP 2006 ABEPRO 1. 


\section{APÊNDICES}

\section{Apêndice A - Organograma da Empresa}

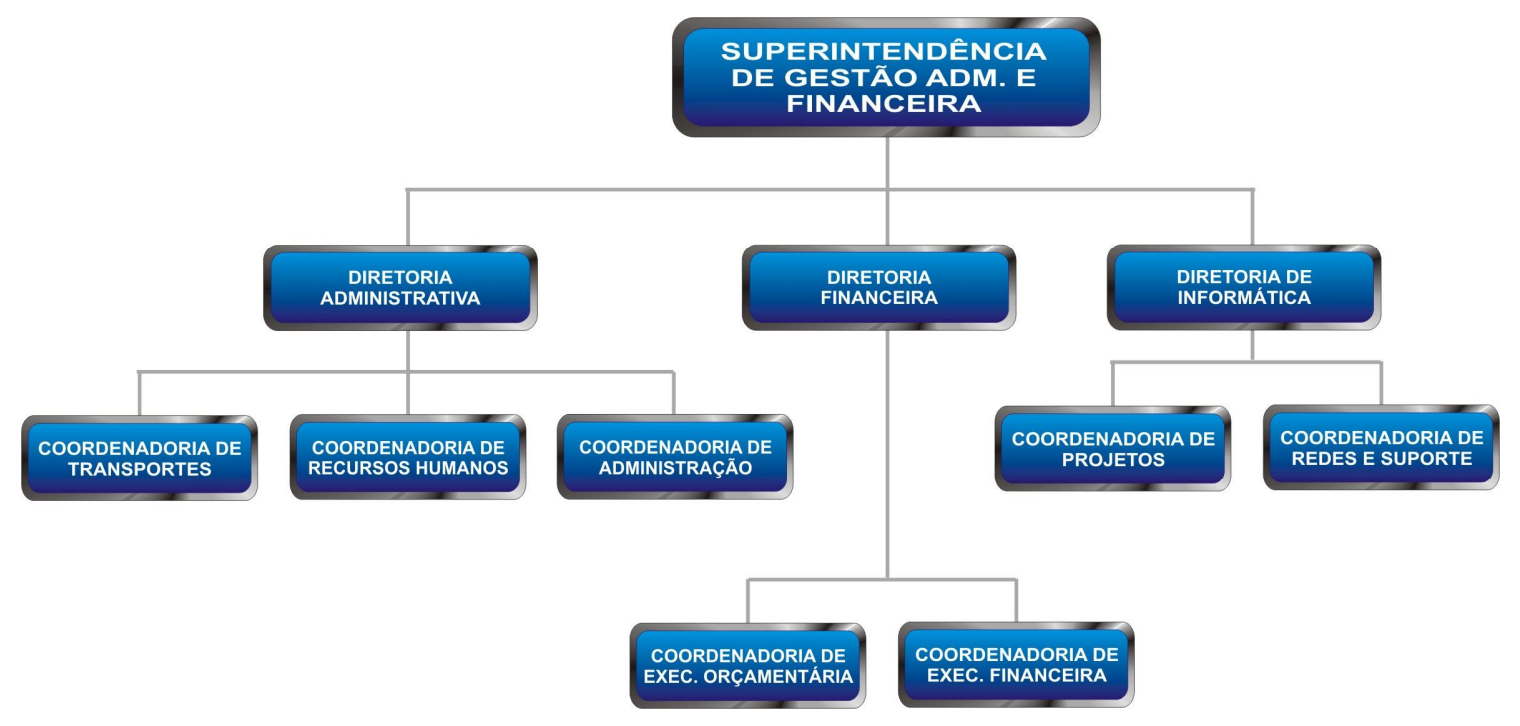




\section{ANEXOS}

\section{Anexo A - Questionário}

Pensando na equipe de trabalho à que você pertence, responda os itens abaixo utilizando a escala de 1 a 5.

\begin{tabular}{|c|c|c|c|c|}
\hline Discordo totalmente & $\begin{array}{c}\text { Discordo } \\
\text { parcialmente }\end{array}$ & $\begin{array}{c}\text { Nem concordo } \\
\text { nem discordo }\end{array}$ & Concordo parcialmente & Concordo totalmente \\
\hline 1 & 2 & 3 & 4 & 5 \\
\hline
\end{tabular}

1- Em relação aos membros da minha equipe de trabalho, eu sinto confiança que manteremos boas relações no futuro.

2- Tenho sentimentos positivos sobre a forma como trabalhamos juntos na minha equipe.

3- Estou satisfeito com a forma em que trabalhamos juntos na minha equipe.

4- Sinto-me bem a respeito do relacionamento que mantenho com os membros da minha equipe de trabalho.

5- Confio completamente nos membros da minha equipe.

Em que medida as sentenças abaixo refletem o que você faz ou sente em relação à sua equipe. Desta vez a escala de respostas mudou, pois vai de 1 a 7.

\begin{tabular}{|l|l|l|l|l|l|l|}
\hline $\begin{array}{l}\text { Discordo } \\
\text { totalmente }\end{array}$ & Discordo & $\begin{array}{l}\text { Discordo } \\
\text { um pouco }\end{array}$ & $\begin{array}{l}\text { Nem concordo } \\
\text { nem discordo }\end{array}$ & $\begin{array}{l}\text { Concordo um } \\
\text { pouco }\end{array}$ & Concordo & $\begin{array}{l}\text { Concordo } \\
\text { totalmente }\end{array}$ \\
\hline 1 & 2 & 3 & 4 & 5 & 6 & 7 \\
\hline
\end{tabular}

1- Conversando com amigos, eu sempre me refiro a minha equipe de trabalho como uma grande unidade para a qual é ótimo trabalhar.

2- Eu julgo que os meus valores são muito similares aos valores defendidos pela equipe de trabalho a que pertenço. 
3- Eu me sinto orgulhoso dizendo às pessoas que sou parte da minha equipe de trabalho.

4- A minha equipe de trabalho realmente inspira o melhor em mim, para o progresso no desempenho das minhas atividades.

5- Eu me sinto contente por ser parte desta equipe, comparando com outras que conheço.

6- Eu realmente me interesso pelo destino da equipe a que pertenço.

7- A minha equipe é a melhor de todas para se trabalhar.

8- Decidir trabalhar nesta equipe foi um erro de minha parte.

9- Eu sinto pouca lealdade para com a equipe em que trabalho. 